\title{
The perception of novice approved clinical instructors on their preparedness as clinical educators
}

Amanda-Jean Hart

West Virginia University

Follow this and additional works at: https://researchrepository.wvu.edu/etd

\section{Recommended Citation}

Hart, Amanda-Jean, "The perception of novice approved clinical instructors on their preparedness as clinical educators" (2009). Graduate Theses, Dissertations, and Problem Reports. 4475.

https://researchrepository.wvu.edu/etd/4475

This Thesis is protected by copyright and/or related rights. It has been brought to you by the The Research Repository @ WVU with permission from the rights-holder(s). You are free to use this Thesis in any way that is permitted by the copyright and related rights legislation that applies to your use. For other uses you must obtain permission from the rights-holder(s) directly, unless additional rights are indicated by a Creative Commons license in the record and/ or on the work itself. This Thesis has been accepted for inclusion in WVU Graduate Theses, Dissertations, and Problem Reports collection by an authorized administrator of The Research Repository @ WVU. For more information, please contact researchrepository@mail.wvu.edu. 
The Perception of Novice Approved Clinical Instructors on Their Preparedness as Clinical Educators.

Amanda- Jean Hart, ATC

Thesis submitted to the College of Physical Activity and Sport Sciences

at West Virginia University in

partial fulfillment of the requirements

for the degree of

Master of Science

In

Athletic Training

Michelle Sandrey, Ph.D., ATC, Chair

Damien Clement, Ph.D., ATC

Elizabeth Bunn, MS, ATC

College of Physical Activity and Sports Sciences

Morgantown, WV

2009

Key Words: Novice Approved Clinical Instructor, Approved Clinical Instructor Workshop, Clinical Education 


\begin{abstract}
The Perception of Novice Approved Clinical Instructors on Their Preparedness as Clinical Educators.
\end{abstract}

By

\title{
Amanda-Jean Hart, ATC
}

Context: Approved Clinical Instructor (ACI) training is an important step in becoming a clinical educator within the field of athletic training, yet research with regards to the effectiveness of this training for certified athletic trainers (ATCs) is lacking. Furthermore, the perception of novice ACIs, who are being increasingly utilized as clinical educators within athletic training programs, on their preparedness to serve in that role has not been extensively researched. Objective: The purpose of this study was to determine novice ACIs' perceptions of their preparedness to teach, supervise and evaluate athletic training students (ATS) after they have completed the ACI training course. Design: The design of this study was a descriptive analysis of novice ACIs' views of their preparedness to work with ATS after completing the ACI training course. Setting: All 365 CAATE accredited Athletic Training Programs (ATEP) in the USA. Participants: This study included thirty eight novice ACIs from 365 Commission on Accreditation of Athletic Training Education (CAATE) accredited ATEPs who have completed the ACI training workshop and have been certified for at least one year and have had three years or less of clinical experience as an ACI. There were a total of 365 emails sent out to the PDs asking them to participate in the study. Of the 365 emails, 37 responses were received equaling a total of 130 novice $\mathrm{ACI}$ email addresses and therefore there was a $29 \%$ return rate. Of the 38 participants who responded to the survey, $52.6 \%(\mathrm{n}=20)$ were GAs. All respondents $(100 \%, \mathrm{n}=38)$ reported being ACIs at their respective institutions. Thirty four percent $(\mathrm{n}=13)$ of the participants had less than one year of experience as an ACI, while $(23.7 \%, \mathrm{n}=9)$ indicated they were ACIs for more then two years. Sixty three percent $(\mathrm{n}=24)$ of the ACIs reported having more than two years experience as an ATC. When respondents were asked about their work settings, $84 \%(n=32)$ reported working in the college/ university setting Intervention: The subjects completed an electronic survey by a link given to them via an e-mail. The survey consisted of a demographics section, content section consisting of student learning styles, ACI responsibilities, evaluation and feedback on student performance, ACI preparation, and overall preparedness. Main Outcomes Measure: Novice ACIs will feel that the ACI training they underwent was not adequate enough to prepare them to supervise, evaluate and teach undergraduate athletic training students based on responses. Additionally, Novice ACIs will not feel sufficiently prepared to be an approved clinical instructor based on responses. Results: With regards to supervising ATSs, $50 \%(\mathrm{n}=19)$ indicated they supervised 2 to 3 undergraduate ATSs. The majority of all of the participants felt prepared in the areas of learning styles, ACI responsibilities, evaluation and feedback of student performance, and ACI preparation. The participants felt most prepared to evaluate ATS clinical knowledge $(61 \%, \mathrm{n}=23)$ and least prepared to evaluate professional behaviors $(47 \%, \mathrm{n}=18)$. The participants felt most prepared to provide feedback in ATS professional behaviors $(34 \%, \mathrm{n}=13)$ and least 
prepared to provided feedback in clinical decision making $(16 \%, \mathrm{n}=6)$. The number one greatest challenge reported as a first year ACI was understanding the institutions policies and procedures $(18.4 \%, \mathrm{n}=7)$. The number two reported greatest challenge was controlling the learning environment $(21.1 \%, \mathrm{n}=8)$ and the third reported greatest challenge was providing feedback on clinical skills $(15.8 \%, \mathrm{n}=6)$. Finally, respondents rated their performance during their first year as an $\mathrm{ACI}\left(M=6.57^{+}-1.0\right)$ using a 10 point Likert scale ranging from 0 being "worst performance" and 10 being the "best

performance." Conclusion: The participants who responded to the questionnaire, mostly felt prepared to be an ACI in their novice years based on responses. Literature has found that teaching, supervising and evaluating behaviors may be a weakness among novice ACIs. Most of the participants felt that the ACI training workshop was beneficial and prepared them to be ACIs, but there were some participants who felt that the training workshop was not beneficial to their development as an ACI. 


\section{ACKNOWLEDGEMENTS}

First and foremost, I would like to thank my family who has been there for me throughout my entire education and entire life. It is because of you that I am where I am today and I sincerely thank and love you.

I would like to thank my committee members, first, Dr. Michelle Sandrey for giving me the opportunity to come to WVU and obtaining my master degree. Dr. Damien Clement, thank you for spending as much time on my research as you did. It is truly appreciated and would not have been completed as well as it was without your efforts. Elizabeth Bunn, thank you so much for not only being there to help me through the writing process but for being there for me as a friend as well.

I would like to thank Dr.Vincent Stilger for allowing me to have the position of educational GA at WVU and therefore helping me to continue my education and grow as a professional.

Lastly, I would like to thank all my undergraduate professors. It is because of all of your conscious efforts and genuine care that I have been able to attend graduate school and complete a master degree to further my education. Thank you all very much. 


\section{TABLE OF CONTENTS}

INTRODUCTION.................................................... 1

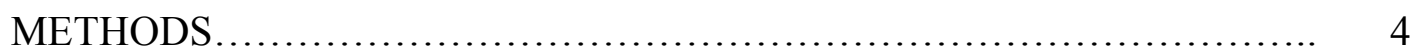

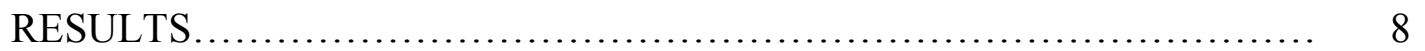

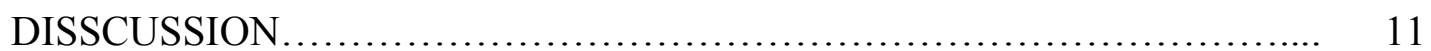

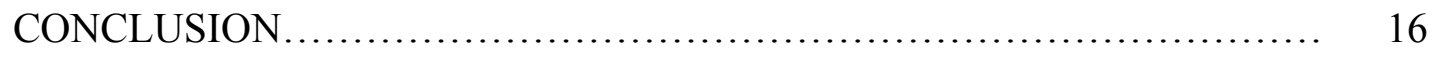

REFERENCES.................................................. 18

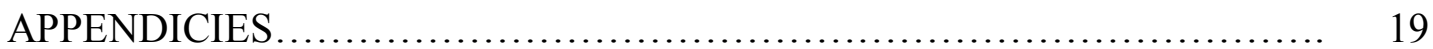

APPENDIX A. THE PROBLEM......................................... 20

APPENDIX B. LITERATURE REVIEW ............................... 27

APPENDIX C. ADDITIONAL METHODS .............................. 51

APPENDIX D. ADDITIONAL RESULTS............................ 61

APPENDIX E. RECOMMENDATIONS FOR FUTURE RESEARCH ....... 69

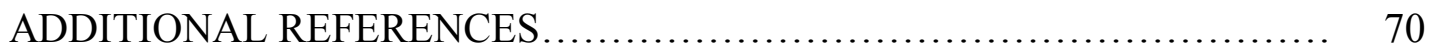




\section{LIST OF TABLES}

C1. Cover Letter to Program Directors.......................................... 51

C2. Cover Letter to Approved Clinical Instructors..............................52

C3. Follow up letter to Approved Clinical Instructors............................53

C4. Questionnaire to Novice Graduate Assistant Approved Clinical Instructors.........54

D1. Demographic Information.............................................61

D2. Learning Styles......................................................62

D3. ACI Responsibilities...............................................63

D4. Evaluation and Feedback of Student Performance............................65

D5. ACI Preparation....................................................... 67

D6. Approved Clinical Instructors Greatest Challenges..............................68 


\section{INTRODUCTION}

Clinical athletic training is a very important aspect of the athletic training student's (ATS's) professional development. ${ }^{1,2}$ During these clinical experiences, ATSs should have opportunities to integrate cognitive and psychomotor competencies, clinical proficiencies, and foundations for professional practice. ${ }^{3}$ However, having good clinical skills based on experience and education as an ATS does not guarantee that a certified athletic trainer (ATC) will be a good approved clinical instructor (ACI). ${ }^{2,4}$ An ACI, according to Weidner, ${ }^{6}$ is an appropriately credentialed professional identified and trained by the program curriculum instructor educator (CIE) to provide instruction and evaluation of the Athletic Training Educational Competencies and/or Clinical Proficiencies. ${ }^{6}$ In order to be an effective ACI, considerable emphasis needs to be placed on proper teaching strategies that may not have been included in the ATC's professional education. Nonetheless, many ATCs do not have the aforementioned preparation in their education and have been chosen for ACI positions based on clinical skills rather than teaching ability.,

In 2000 the first seminars for CIEs were developed to provide both ATCs and program directors (PDs) with necessary information and resources to serve as CIEs for their institutions. Approved clinical instructors were then trained by the CIEs to effectively teach and evaluate ATSs' clinical proficiencies. ${ }^{2,3}$ Upon completion of this training; ACIs are expected to be able to assess student performance. This student assessment should provide the necessary information for the ACI to design any missing learning experiences as well as modify the information already in place, in addition to providing academic information to the ATS. ${ }^{5}$

To become an ACI, an ATC is required to have at least one year of experience. However, some Commission of Accreditation of Athletic Training Education (CAATE) 
programs rely on ATCs with less then one year of experience to provide students with supervision in the clinical setting. In research conducted by Stemmans and Ganstead ${ }^{7}$ it has been shown that in order to be an effective educator experience is vital. Stemmans and Gangstead ${ }^{7}$ further noted that "novice teachers expressed a significant amount of indecision and lack of pedagogic content and demonstration ability." Additionally, they also found that experienced educators provided a better learning environment with feedback and better instruction. ${ }^{7}$ Finally, students initiated interactions less frequently with novice ACIs rather then more experienced ACIs, confirming that teaching efficacy increases with teaching experience.

Stemmans and Gangstead ${ }^{7}$ acknowledged that one of the major problems with novice ACIs is that within their first year of certification and professional practice ATCs are limited to the number of sports injuries requiring medical care. With more experience these ATCs would be able to give a more detailed and accurate perspective. Another potential problem with novice ACIs, Stemmans and Gandstead ${ }^{7}$ highlighted was their increased tendency to confuse a teaching situation with a non-teaching situation thus hindering ATSs' participation and consequently their education. $^{7}$ It is believed that a more experienced ACI would be able to distinguish between these situations and allow student participation thus permitting learning. Due to the aforementioned findings, Stemmans and Gangstead ${ }^{7}$ suggested that specific attention should be given to inexperienced ACIs in order to promote effective learning for ATSs and decrease the chances of incompetence and poor supervision in the athletic training room. Therefore, given the results with regards to novice ACIs and their lack of preparedness, workshops to help prepare them for their roles as ACIs are very important in supporting the development of effective instruction techniques. $^{7}$

Further research conducted by Henning, ${ }^{8}$ corroborated the study of Stemmans and 
Gangstead. ${ }^{7}$ Henning ${ }^{8}$ found that novice ACIs have been showing signs of incompetence in their roles at institutions serving as ATS educators. Henning ${ }^{8}$ stated that ATCs who are acting as ACIs in the clinical setting are balancing many different roles and as a result are experiencing role strain because of it. Henning ${ }^{8}$ further suggested that a novice ACI due to their lack of work experience would encounter more difficulty at balancing their roles when compared to a more experienced ACI who has had more time developing appropriate coping strategies. Consequently, novice ACIs abilities to serve as ATSs educators would be affected.

Seegmiller ${ }^{9}$ supported this assertion by stating that having appropriate teaching, supervisory, and evaluation skills are not entry level abilities. Seegmiller ${ }^{9}$ further noted that novice ACIs who possess a lack of professional experience could be detrimental to the quality of ATSs' education by placing those individuals in teaching roles. This is even more concerning when one considers that novice ACIs are filling more and more clinical education positions. Seegmiller ${ }^{9}$ believes that an ATC should have at least 3 years of experience before becoming an $\mathrm{ACI}$ since these positions require experience to develop, and all too often novice ACIs are left to develop these skills individually. ${ }^{9}$

Current research conducted to evaluate novice graduate assistant (GA) ACIs perceived preparedness was conducted by Pircher. ${ }^{10}$ Using a population of GA novice ACIs who were at CAATE accredited programs for more then five years, Pircher $^{10}$ assessed novice GA ACIs learning styles, evaluation of student performance and ACI preparation. Results revealed that $87.9 \%$ of the novice GA ACIs felt that a variety of learning styles were incorporated into ACI training. Additionally, 79\% agreed that information they received on learning styles during their ACI training workshop prepared them to identify the different learning styles utilized by ATSs. Furthermore, the majority felt that they were aware of the characteristics needed to be an 
effective ACI. ${ }^{10}$ Novice GA ACIs also felt confident that their clinical instruction was tailored to fit the learning styles of the ATSs and that they were able to differentiate between the ATSs learning styles and utilize the appropriate teaching styles. ${ }^{10}$ Overall the result of this study found that novice GA ACIs felt they possessed good clinical skills and knowledge to serve as ACIs, demonstrated ethical behaviors, and confidence in communication skills. Novice GAs also felt that they were able and prepared to evaluate the ATS's skills and performance. ${ }^{10}$

Pircher's ${ }^{10}$ study also revealed that novice GA ACIs perceived that the training they received was adequate enough for them to supervise, teach, and evaluate ATSs. However, in related literature by Stemmans and Gangstead ${ }^{7}$ and Henning ${ }^{8}$ it was noted by ATSs and more experienced ACIs with the inclusion of PDs, that novice ACIs do not have the necessary skills and knowledge to effectively supervise ATSs. Stemmans and Gangstead ${ }^{7}$ also found that ATSs would prefer a more experienced ACI while Henning ${ }^{8}$ found that novice ACIs were showing signs of incompetence at their jobs. As a result of the contradictory information on this critical topic, further investigation as to why experienced ACIs and ATSs feel that novice ACIs are not prepared for their roles while novice ACIs feel they are prepared, needed to be further evaluated. A comparative look at current ACI training consistency and what the research considers to be good ACI qualities would be beneficial to enhance the clinical evaluation and teaching skills of novice ACIs. Consequently, the primary purpose of this investigation was to determine whether novice ACIs feel they are adequately prepared to teach, evaluate and supervise ATSs during their clinical experience after completion of the ACI training workshop.

\section{METHODS}

The design of this study was a prospective descriptive analysis, to identify novice ACIs perceptions of their preparedness to supervise ATSs during their clinical education experience. 
This analysis examined the responses of novice ACIs from a 48-item online questionnaire, which contained two categories; demographic information and learning styles.

Participants

Program directors at 356 institutions that were CAATE accredited undergraduate ATEPs were contacted in regards to their novice ACIs. Contact information was requested from the PDs in order to obtain the sample for the current study. There were a total of 365 emails sent out to the PDs asking them to participate in the study. Of the 365 emails, 37 responses were received equaling a total of 130 novice $\mathrm{ACI}$ email addresses and therefore there was a $29 \%$ return rate. Of the 38 participants who responded to the survey, $52.6 \%(\mathrm{n}=20)$ were GAs. All respondents $(100 \%, \mathrm{n}=38)$ reported being ACIs at their respective institutions. Thirty four percent $(\mathrm{n}=13)$ of the participants had less than one year of experience as an ACI, while $(23.7 \%, \mathrm{n}=9)$ indicated they were ACIs for more then two years. Sixty three percent $(\mathrm{n}=24)$ of the ACIs reported having more than two years experience as an ATC. When respondents were asked about their work settings, $84 \%(n=32)$ reported working in the college/ university setting. With regards to supervising ATSs, $50 \%(n=19)$ indicated they supervised 2 to 3 undergraduate ATSs. Eighty percent $(\mathrm{n}=30)$ reported working in a setting where other ACIs were also supervising ATSs. Sixty eight percent $(n=26)$ reported not being directly supervised on a daily basis by a staff ATC. Finally, $57.9 \%(\mathrm{n}=22)$ of the participants who completed the survey reported that they were not supervised by a GA ACI during their own undergraduate experience. Additional demographic characteristics can be located in Table D1.

Inclusion criteria for participation in the study included, participants must have been an ATC who has been certified for at least one year, have attended an ACI training workshop at their respective institution and had a minimum of one and a maximum of three years of clinical 
experience. Furthermore, during the course of the study participants must have been evaluating and supervising ATSs. Exclusion criteria for the study included those institutions who did not have novice ATCs evaluating and supervising undergraduate ATSs. Other exclusion criteria included ACIs who were not considered to be a novice ACI according to the definition of the study. This study was approved by the institutions Office of Research Compliance at West Virginia University.

Instrumentation

The questionnaire utilized in the study was created by Pircher, ${ }^{11}$ after reviewing areas related to the study such as the ACI training workshop, clinical education literature, and best clinical practice. The questionnaire consisted of two sections: demographic information and content. The demographic information consisted of multiple choice questions inquiring if the individual was a graduate student, if he/she was an ACI, years as an ACI, number of years as an ATC, and current clinical placement/ setting. The survey also included questions which solicited the number of ATSs that the individual was supervising, if the ACI was supervised by another ACI, if he/she was directly supervised by a staff ATC, and whether or not the participant was supervised by an ACI during his/ her undergraduate clinical education. The content section of the questionnaire consisted of the following items including learning styles, ACI responsibilities, evaluation and feedback of student performance and ACI preparation.

Pircher $^{11}$ stated that the "questionnaire was pilot tested by two CAATE undergraduate program directors and five ATCs at National Collegiate Athletics Association (NCAA) Division I, II and III institutions for readability and clarity. Furthermore, a psychometric statistical expert experienced in questionnaire development also reviewed the questionnaire for face and content validity. Several drafts of the questionnaire were created and revisions were made following 
feedback from the pilot study." Please refer to Table C4 for a copy of the questionnaire. Procedures

Selection of the participants began by identifying higher education institutions with an ATEP that was accredited by referencing the CAATE website. From those institutions $(n=$ 365), the investigator acquired the undergraduate PD's name and e-mail address from the CAATE website. Once obtained, a cover letter was sent via e-mail to the undergraduate PDs' institutions inquiring whether they have novice ACIs evaluating and supervising their ATSs, if they were interested in participating in the study, and if they would provide their novice ACIs' email addresses to the investigator (Table C1). Some PDs did not feel comfortable supplying that information to the investigator and forwarded the cover letter to the novice ACIs to allow them to decide if they wanted to participate. Other PDs who were not comfortable with the study, simply declined to participate or did not allow their novice ACIs to participate.

Once PDs agreed to participate in the study by providing e-mail addresses for their novice ACIs, a cover letter was sent via e-mail explaining the nature of the study (Table C2). This cover letter also included a link to the questionnaire online. If novice ACIs were willing to participate, they were then asked to follow the link to simple forms in order to complete the questionnaire by either clicking on the best corresponding answer or by ranking the answers.

After a two week period novice ACIs were contacted again via e-mail as a reminder to participate (Table C3). All of the data obtained via the questionnaires was returned to the researcher via an e-mail that was addressed as anonymous for the confidentiality of the participants. The data was then placed into an Excel spreadsheet and later into SPSS for analysis. All data was analyzed using SPSS Version 16.0 for Windows. (SPSS Inc. Chicago, IL.)

The online questionnaire was housed on the university server, which, by using a firewall, 
protected data in transit from outside observation. The results of the questionnaire were automatically processed by a Common Gateway Interface (CGI) server, which was protected by the firewall and was accessible only to two university Web masters. The data was processed in the working memory of the CGI server and was not stored onto a disk; after being processed the data no longer existed on the CGI server. The CGI server automatically sent the data via e-mail to the researcher where it was saved in a locked file. Precautions were taken to maintain anonymity of data.

Statistical Analysis

For the data analysis, the questionnaire was divided into the existing five sections (demographic characteristics, learning styles, ACI responsibilities, evaluation and feedback of student performance, and ACI preparation). An additional section, ACI greatest challenges was created for data analyses purposes. Responses of the novice ACIs at the CAATE accredited institutions were analyzed using descriptive statistics. This included frequencies and percentages of responses for the questionnaire items. All data was analyzed using SPSS Version 16.0 for Windows. (SPSS Inc. Chicago, IL.)

\section{RESULTS}

Learning Styles

In the learning styles category, $39.5 \%(n=15)$ strongly agreed or agreed $(50 \%, n=19)$ that there were various learning styles presented during their ACI training workshop. Eighteen percent $(\mathrm{n}=7)$ strongly agreed or agreed $(61 \%, \mathrm{n}=23)$ that the information received on learning styles during the ACI training workshop enhanced their ability to identify the different learning styles utilized by ATSs. In addition, $15.8 \%(\mathrm{n}=6)$ strongly agreed or agreed $(65.8 \%, \mathrm{n}=25)$ that clinical instruction was tailored to fit the learning style of the ATSs that were supervised. The 
majority of the participants $(57.9 \%, \mathrm{n}=22)$ felt able to differentiate between learning style and teaching style with $15.8 \%(n=6)$ strongly agreeing and $57.9 \%(n=22)$ agreeing on the ability to do so. Additional learning style results can be located in Table D2.

ACI Responsibilities

Sixty three percent $(n=24)$ of the participants agreed to have the clinical knowledge to serve as an effective ACI. As $55.3 \%(n=21)$ agreed to having the clinical skills, and $60.5 \%$ $(n=23)$ agreed with the ability to be an effective professional mentor. A total of $36.8 \%(n=14)$ of ACIs strongly agreed or agreed $(50 \%, n=19)$ on having a good understanding of their institutions athletic training policies and procedures. Additional ACI responsibilities results can be located in Table D3.

Evaluation and Feedback of Student Performance

The results indicated that most of the participants strongly agreed $(28.9 \%, \mathrm{n}=11)$ or agreed $(63.2 \%, n=24)$ on preparation to evaluate an ATSs' first clinical proficiency. When respondents were asked to rate evaluation skills, $36.8 \%(n=14)$ strongly agreed or agreed $(60.5 \%$, $\mathrm{n}=23$ ) on feeling confident in evaluating an ATS's clinical knowledge. Additionally, a total of $97 \%$ either strongly agreed $(42.1 \%, n=16)$ or agreed $(55.3 \%, n=21)$ on being confident in evaluating ATSs clinical skills. Finally, 47.4\% $(\mathrm{n}=18)$ both strongly agreed and agreed in feeling confident in evaluating a student's professional behavior.

Participants strongly agreed $(47.4 \%, n=18)$ or agreed $(50 \%, n=19)$ on preparation to provide effective positive feedback, and strongly agreed $(42.1 \%, \mathrm{n}=16)$ or agreed $(50 \%, \mathrm{n}=19)$ on being prepared to give effective constructive feedback to an ATS to help improve performance. Forty percent $(n=15)$ strongly agreed or agreed $(55.3 \%, n=21)$ on feeling confident in providing students feedback on clinical knowledge. Furthermore, $40 \%(n=15)$ strongly agreed 
or agreed $(57.9 \%, \mathrm{n}=22)$ in feeling confident to provide students feedback on clinical skills. Forty five percent $(n=17)$ strongly agreed and $52.6 \%(n=20)$ agreed in feeling confident to provide student feedback on professional behavior. Forty two percent $(n=16)$ strongly agreed or agreed $(55.3 \%, \mathrm{n}=21)$ in feeling confident in providing student feedback on clinical decision making. Finally, when respondents were asked where most confidence was evident in providing feedback, 34.2\% $(n=13)$ responded professional behaviors, $31.6 \%(n=12)$ responded clinical skills, 18.4\% $(\mathrm{n}=7)$ clinical knowledge, and 15.8\% $(\mathrm{n}=6)$ clinical decision making. Additional evaluation and feedback results can be located in Table D4.

\section{ACI Preparation}

Of the population sampled, $28.9 \%(n=11)$ agreed on being aware of the characteristics of an effective clinical instructor and being able to use those characteristics to become a better ACI, in addition to understanding the "teaching and learning over time concept". When participants were asked if the ACI training workshop provided at the institution prepared them to be an effective ACI for the first year, $18.4 \%(n=7)$ strongly agreed, $39.5 \%(n=15)$ agreed, and $15.8 \%$ $(n=6)$ disagreed. Additionally, when asked if they felt the ACI training workshop was beneficial, $18.4 \%(n=7)$ strongly agreed, $42.1 \%(n=16)$ agreed, while $13.2 \%(n=5)$ disagreed. When the participants were asked to rate if an ATC with one year of clinical experience upon the completion of an ACI training workshop should serve as an ACI, 13.2\% $(n=5)$ strongly agreed, $36.8 \%(n=14)$ agreed, while $23.7 \%(n=9)$ disagreed and $2.6 \%(n=1)$ strongly disagreed.

Additional ACI preparation results can be located in Table D5.

\section{ACI Greatest Challenges}

Of the participants who completed the survey $(n=38), 4$ participants did not complete this question, therefore there were only 34 usable responses $(n=34)$. Three participants reported that 
there were no challenges reported as a first year ACI. The number one greatest challenge reported as a first year ACI was understanding the institutions policies and procedures (18.4\%, $\mathrm{n}=7$ ). The number two reported greatest challenge was controlling the learning environment $(21.1 \%, \mathrm{n}=8)$, and the third reported greatest challenge was providing feedback on clinical skills $(15.8 \%, \mathrm{n}=6)$. Finally, respondents rated their performance during their first year as an ACI $(M=$ 6.57+- 1.0) using a 10 point Likert scale ranging from 0 being "worst performance" and 10 being the "best performance." Additional ACI greatest challenges results can be located in Table D6. DISCUSSION

The primary purpose of this study was to determine if completion of ACI training workshop adequately prepared novice ACIs to teach, supervise and evaluate ATSs. This study was conducted because of the lack of previous research in regards to novice ACIs and if perception of being adequately prepared to supervise ATSs was evident. There is existing research conducted on what good qualities and personality $\operatorname{traits}^{1}$ an ACI should have but limited research has been conducted with regards to if an ACI felt that the ACI training workshop provided the skills necessary to teach, evaluate and supervise ATS. What little research exists is contradictory and further investigation as to why experienced ACIs and ATSs feel that novice ACIs are not prepared for their roles while novice ACIs feel they are prepared, needed to be further explored. Therefore the hypothesis for the study was: novice ACIs will feel that the ACI training they underwent was not adequate enough to prepare them to be effective educators to ATSs.

In the learning styles section of the questionnaire about $90 \%$ of participants strongly agreed or agreed that a variety of learning styles were presented in the ACI training workshop thus presumably preparing novice ACIs to identify the different learning styles of ATSs. 
Similarly, Pircher ${ }^{10}$ found that approximately $89 \%$ of the participants strongly agreed or agreed that a variety of learning styles were presented in the workshop as well. Consequently, it can be concluded that ACI training workshops are probably providing novice ACIs with a broad range of different learning styles during training. Coker ${ }^{11}$ confirmed the importance of learning styles within the educational context by stating that is it extremely important for clinical instructors to be able to know and understand the different learning styles among undergraduate students in order to be effective educators. Knowing what the different learning styles are and more importantly being able to tailor one's teaching and instructional methods towards ATSs learning styles is important because without this skill the ATSs education will suffer and may be unable to learn in the environment in which the ACI is teaching.

Since the population as previously mentioned, strongly agreed or agreed that a variety of learning styles were presented in their ACI workshop it was no surprise that the majority of the novice ACIs that participated in this study believed in the ability (61\%) to identify the different types of learning styles that ATSs possessed and thus were able to differentiate between learning and teaching styles (58\%). Pircher ${ }^{10}$ found that approximately $80 \%$ strongly agreed or agreed on being able to distinguish between learning and teaching styles. However, in previous literature Seegmiller ${ }^{9}$ stated that understanding how to teach and differentiate between styles are not entry level abilities and further experience is needed to be a successful educator. Based on what the literature is stating, even if the ACI workshops are providing the novice ACIs with the information it would still be difficult for a novice to be able to use this information for the intended purpose. Understanding how to cater to different learning styles is a skill that comes with experience and is not an entry level ability. So, although ACI training workshops may be providing this information to the novice ACIs, a few years of experience before the skill can be 
used clinically may be necessary.

Most of the participants reported on possessing the clinical knowledge (95\%) and skills $(92 \%)$ that are needed to serve as an effective ACI, which is similar to what Pircher $^{10}$ found in his study. Pircher ${ }^{10}$ found that $100 \%$ of the participants agreed on possessing both clinical knowledge and skills to serve as an effective ACI. Again, the findings from the current study and previous research by Pircher $^{10}$ appear to be in stark contrast to previous research. Henning ${ }^{8}$ performed a study which consisted of 118 head, assistant and GA ACIs from the college setting from her questionnaire she found that novice GA ACIs had poor time management, patient care, clinical education, administrative work and personal education. Henning ${ }^{8}$ suggested that with experience comes the ability to self reflect on performance and to learn how to improve in what is lacking. Consequently, she assumed that in time novice ACIs would be able to improve upon these skills. It must be stated though that there appears to be a discrepancy between novice ACIs perceptions of the abilities and the research perception/assessment of their abilities.

The evaluation and feedback of student performance section of the questionnaire revealed that novice ACIs felt prepared to evaluate proficiencies (92\%) as well as clinical skills (97\%), knowledge (98\%) and professional behavior (94\%). In fact, when given a choice of the above listed characteristics, novice ACIs reported that they were most comfortable in providing feedback on ATSs professional behaviors (34\%). On the other hand, Pircher $^{10}$ noted that $100 \%$ of participants felt confident in evaluating a student's clinical knowledge and skills but only $88 \%$ of the participants felt comfortable in evaluating professional behaviors. Craig ${ }^{12}$ believes that many of the professional characteristics that are required as an ATC are not easily taught and must be learned through experience and student encounters. It was interesting that the population of ATCs, which had the least amount of professional experience, felt most confident 
in that category. A presumable reason for this could be that novice ACIs may feel the need to compare the expertise among the more experienced ATCs and ACIs and therefore tend to overestimate their abilities. This is similar to Stemmans and $\mathrm{Gangstead}^{7}$, as novice ACIs feel the need to constantly demonstrate their knowledge and skills.

Participants agreed on being prepared to provide positive feedback and give constructive feedback to an ATS to help improve performance on clinical skills (98\%), professional behaviors (98\%), clinical decision making (98\%) and clinical knowledge (95\%). When the respondents were specifically asked in which of the previously stated categories they felt the most confident in providing feedback, the highest rated categories were professional behaviors (34\%) and clinical skills (30\%). However, Pircher ${ }^{10}$ found that respondents rated professional behaviors the lowest score (9\%), while clinical skills was rated the highest $(67 \%)$. Craig ${ }^{12}$ found that within each ATEP, a variety of ACIs commonly serve as a professional role model. As a result, ACIs will naturally demonstrate professionalism differently. Thus, regardless of presentation in the classroom, student learning of professionalism will fluctuate with clinical placements. It is difficult to determine the reason for the conflicting information between the current study and Pircher's ${ }^{10}$ results. The question that must be asked as a result is, how are novice ACIs gaining the ability to provide ATSs with feedback on professional behaviors when most have only recently began their professional career? Novice ACIs may be using experience from undergraduate professors, clinicians or other professionals encountered in the mentoring process. This may or may not be problematic based on the professional behaviors of the mentors in which they are replicating. Thus, if these behaviors are as important as the research implies, then this may be a serious concern in ATSs education. 
When asked if the novice ACIs felt that overall the ACI training workshop prepared them to be an effective ACI in their first year as well as had beneficial qualities as an ACI, $40 \%$ felt that the workshop prepared or benefited them as a novice ACI. Twenty-six percent were neutral on the topic, while $18 \%$ strongly agreed and $16 \%$ disagreed. Pircher $^{10}$ found that $55 \%$ of his responses agreed that they felt prepared and only $9 \%$ disagreed and 3\% strongly disagreed in feeling prepared during the first year. A probable reason for the discrepancy between the literature which stated that novice ACIs are not prepared for their roles and results of the current study which found that novice ACIs felt prepared could be due to novice ACIs being over confident in their skills and abilities while more experienced ACIs are able to be more self reflective. Experienced ACIs are able to look at themselves and their supervisory skills more objectively then a less experienced ACI. It appears that even though the quantitative results indicate that novice ACIs are prepared to an extent, the comments reflect otherwise. A comment written by one of the participants stated "I think that the ACI training program does not adequately prepare ATCs to teach ATSs. People who are good teachers will be successful without the ACI training, and people who are poor teachers will not improve through the ACI training." Another replied "I feel like my experiences as a student have had the biggest impact on my effectiveness as an ACI. The ACI Workshops are a good refresher, but are not adequate tools for preparing ACI's for future duties. Since most universities do not pay their ACI's, the best ACI's are the ones that get a personal satisfaction from teaching/mentoring students."

Thirty-seven percent of the participants felt that an ATC with only one year of experience and completion of the ACI training workshop should serve as an ACI while $13 \%$ strongly agreed and the remaining $50 \%$ were either neutral or in disagreement with this statement. Pircher ${ }^{10}$, however, found that $88 \%$ either strongly agreed or agreed that an ACI with only one year of 
experience and completion of the ACI training workshop should serve as an ACI. In contrast, Seegmiller ${ }^{10}$ believed that an ACI should have at least 3 years of professional experience because teaching, supervisory and evaluative skills are not entry level abilities. He believed that this can be detrimental to the education of ATSs and that those who lack professional experience are not ready to become educators. Based on the previously stated information and what has been found in the literature, it may be damaging to the student's education as novice ACIs lack experience which would have allowed them to perfect teaching and supervisory skills. Consequently, students may be missing out on information or missing learning experiences because novice supervisors are not recognizing a learning experience or not understanding specific learning styles.

The limitations to this study are that the participants will ATCs who have recently had ACI training and will only have had one to three years of clinical experience. This is interaction and selection biases because the group is selected on a specific characteristic and so it may only be generalizable to this specific group of novice ACIs. Other limitations were that the questionnaire was sent electronically to the participants who had the option in participation causing the sample size to be limited and therefore cannot be generalizable to the population as well. It is understood that student's clinical education is an important component in athletic training education but the mentoring skills developed by training of novice ACIs has not been proven to be adequately effective. Gaining a better understanding of how novice ACIs perceive the training sessions to have helped them could reveal valuable information which could be used to improve future training sessions. The clinical significance is that novice ACIs feel prepared to be effective clinical instructors for ATSs but may not be competent in this position. Therefore, ATSs education may be suffering as a result and producing poor education and learning 
environments.

CONCLUSION

The conclusion of the study was immensely different from what was expected. The majority of novice ACIs felt prepared to teach, supervise and evaluate ATSs. This is in contrast to other studies in which novice ACIs were not performing well as clinical instructors and that student's education may be suffering from this. Some of the participating novice ACIs felt that the ACI training workshop did not benefit them and that novice ACIs should not be placed in the role as a clinical educator until more experience is gained. These discrepancies may exist as the majority of novice ACIs might be overestimating abilities based on the results of the current study. Some novice ACIs may have created personal ideas of what good clinical instruction and supervision are or are using past experiences from undergraduate school. Either option is not suitable to rely on for the education of future ATSs. Although the subject population was small and not representative of all novice ACIs, some generalizations can be made. Even though some novice ACIs did not feel that the ACI training workshop adequately prepared them, the majority of novice ACIs felt prepared to teach, supervise and evaluate ATSs despite the conflicting information in the literature that novice ACIs are not prepared. Therefore further investigation needs to be conducted using a larger population size. 


\section{REFERENCES}

1. Curtis N, Helion JG, Domsohn M. Student athletic trainer perceptions of clinical supervisor behaviors: a critical incident study. J Athl Train. 1998;33(3):249-253.

2. Weidner TG, Henning JM. Importance and applicability of approved clinical instructor standards and criteria to certified athletic trainers in different clinical education settings. $J$ Athl Train. 2005;40(4):326-332.

3. Weidner TG, Noble GL, Pipkin JB. Athletic training students in the college/ university setting and the scope of clinical education. J Athl Train. 2006;41(41):422-426.

4. Weidner TG, Henning JM. Development of standards and criteria for the selection, training, and evaluation of athletic training approved clinical instructors. J Athl Train.

2004;39(4):335-343.

5. Weidner TG, Henning JM. Being an effective athletic training clinical instructor. Athl Ther Today. 2002;7(5):6-11.

6. Weidner TG, Henning JM. Historical perspective of athletic training clinical education. $J$ Athl Train. 2002;37(4):222-228.

7. Stemmans CL, Gangstead SK. Athletic training students initiate behaviors less frequently when supervised by novice clinical instructors. J Athl Train. 2002;37(4):255-260.

8. Henning JM, Weidner TG. Role strain in collegiate athletic training approved clinical instructors. J Athl Train. 2008;43(3):275-283.

9. Seegmiller JG: A model for clinical education in athletic training. The Intern J Allied Health Sci and Prac. 2003. Volume 1 Number 1.

10. Pircher CM. Perceived Preparedness of Graduate Assistant Novice Approved Clinical Instructors for Supervision of Undergraduate Athletic Training Students. [master's thesis]. Morgantown, WV: West Virginia University; 2008.

11. Coker CA. Consistency of learning styles of undergraduate athletic training students in the traditional classroom versus the clinical setting. J Athl Train. 2000;35:441-444.

12. Craig DI. Learning professionalism in athletic training education. Athl Train EDC J. 2006;1(Jan-Mar):8-11. 
APPENDICIES 


\section{APPENDIX A}

\section{THE PROBLEM}

\section{Research Question}

Athletic training education is a combination of both classroom and clinical settings. In the classroom there is a lecture format of teaching which only allows for descriptions of what is being taught. The clinical setting is an opportunity for hands on learning and actual practice of skills. ${ }^{13}$ It is widely known that clinical education can be more valuable to a student than classroom lectures. $^{13,14,15}$

An approved clinical instructor (ACI) is responsible for the clinical education of the athletic training student (ATS). In order to become an ACI, an individual must be a certified athletic trainer (ATC) for a minimum of one year and have taken the institutions ACI training course. Many of the current ACIs educating ATSs are considered novice ACIs because of their lack of experience teaching ATSs in the clinical setting. "Prior to the $2002-2003$ academic years all instructors were considered clinical instructors as there were no clinical proficiencies to evaluate. In addition to supervising the students, the ACI provided instruction and evaluation of the athletic training educational competencies and/or clinical proficiencies." ${ }^{16}$ Since then, clinical proficiencies have been introduced and the role of the clinical instructor has taken on much more responsibility as it has been revealed how vital they are to ATSs' education. ${ }^{16}$

There have been several studies in the literature focusing on clinical traits for successful ACIs. ${ }^{14,15,17}$ This has become evident since possessing good clinical skills does not necessarily mean that an individual will be an equally good clinical instructor. Professionalism and leadership are two of the more important characteristics for an ACI to have according to the literature. Displaying good clinical behaviors will provide traits for the students to role 
model. ${ }^{15,17}$ Veteran ACIs are theorized to have these good clinical behaviors necessary for students to emulate but novice ACIs lack the experience the literature finds to be very important in order to be an effective ACI.

It is important to understand and know that ACI training should be adequate if not above average to ensure that prospective ACIs are learning techniques to teach and evaluate ATSs. The Commission on Accreditation of Athletic Training Education (CAATE) stated that proper training sessions must be provided to ATCs who will be supervising and teaching ATSs in the clinical setting. Under the National Athletic Training Association Education Council (NATAEC) CIE seminars have been developed with the hope of providing PDs and clinical coordinators the information needed to become the CIE at an institution who would then train the ATCs to teach and evaluate ATSs. ${ }^{13,18}$ However, since each CAATE accredited program is unique, there has been no standardization of these training sessions, only suggested content.

As ATSs graduate and pass the Board of Certification (BOC) exam, they are faced with the decision to work or further education. For those who decide that graduate school is the next step, then the opportunity exists to work as a graduate assistant (GA) clinically and to take classes towards the completion a master's degree. As a graduate assistant certified athletic trainer at a school with an undergraduate ATEP comes the responsibility of working with ATSs and must therefore go through the training needed to teach and evaluate proficiencies. As a first year GA some may not feel ready to take on this responsibility and may want more detailed training to build confidence. It should be known in the athletic training community how GAs as well as novice ACIs feel they are performing because it can affect the future of undergraduate ATS. Henning ${ }^{20}$ stated that several studies agreed that years of experience may be related to role incompetence and that novice ACIs initiated active learning behaviors with their ATSs less often 
than more experienced ACIs. Seegmiller ${ }^{21}$ and Stemmans ${ }^{19}$ have both found that novice ACIs are not ready to take on teaching responsibilities due to a lack of professional experience. Furthermore, Stemmans ${ }^{19}$ found that ATSs are less likely to initiate interactions with novice ACIs and prefer to interact with a more experienced ACI.

Pircher ${ }^{11}$ conducted a study on the perceived preparedness of GA ACIs and found that within this population GA ACIs felt their training was adequate enough and they were confident in evaluation and supervisory skills. ${ }^{11}$ However, due to a limited population and sample size the results from this study are not generalizable to the entire population of novice ACIs and therefore further research in this area is needed.

It is important for each novice ACI to be confident in what is being asked of them and that they are prepared for the responsibility of teaching, evaluating and supervising ATSs because it has been shown in the clinical settings that novice ACIs become involved in situations where they are not sure what to do or what a teachable moment is. Therefore, the research question is:

Do all newly appointed novice ACIs who have been certified for at least one year and have undergone $\mathrm{ACI}$ training feel that the training was adequate enough to function as an approved clinical instructors to undergraduate ATS?

\section{Experimental Hypothesis}

1. Novice ACIs will feel that the ACI training they underwent was not adequate enough to prepare them to supervise, evaluate and teach undergraduate athletic training students based on responses.

2. Novice ACIs will not feel sufficiently prepared to be an adequate approved clinical instructor based on responses. 
Assumptions

1. All participants will answer all questions honestly and to the best of their ability.

2. The participants will answer each question fully.

3. The questionnaire that will be used is assumed to be reliable and valid.

4. The participants will complete and return the questionnaires in a timely manner.

5. All participants will meet inclusion criteria and not exclusion criteria.

Delimitations

1. The results of the questionnaire was limited to only Novice ACIs who were chosen at specific colleges/universities and cannot be generalized to the entire population of ACIs.

2. The results of the questionnaire was limited to only novice ACIs with one to three years of ATC experience and therefore cannot be generalized to more experienced ACIs.

Operational Definitions

1. Approved Clinical Instructor (ACI)- An appropriately credentialed professional identified and trained by the program CIE to provide instruction and evaluation of the Athletic Training Educational Competencies and/or Clinical Proficiencies. ${ }^{18,19}$

2. ATEP- Athletic Training Education Program

3. Athletic Training Student (ATS)- A student enrolled in the athletic training major or graduate major equivalent. 18

4. Certified Athletic Trainer (ATC)- Certified Athletic Trainers are healthcare professionals who are experts in injury prevention, assessment, treatment and rehabilitation, particularly in the orthopedic and musculoskeletal disciplines. ${ }^{18,20}$

5. Commission on Accreditation of Athletic Training Education (CAATE)- Provide comprehensive accreditation services to institutions that offer athletic training degree programs and verify that all CAATE-accredited programs meet the acceptable educational standards for professional (entry-level) athletic training education. ${ }^{18,20}$

6. Clinical Coordinator- The individual program may designate a certified athletic trainer as having the primary responsibilities for the coordination of the clinical experience activities associated with the ATEP. The clinical coordinator position is currently recommended, but not required by the Standards. ${ }^{18}$ 
7. Clinical Education- The portion of the athletic training student's professional preparation that involves the formal acquisition, practice and evaluation of clinical proficiencies through classroom, laboratory, and clinical experiences in medical care environments. $^{18,19}$

8. Clinical Instructor (CI)- An individual identified to provide supervision of athletic training students during clinical experience. ${ }^{18,21}$

9. Clinical Instructor Educator (CIE)- A certified athletic trainer recognized by the institution as the individual responsible for ACI training. If more than one individual is recognized as a CIE for an ATEP, then at least one of those individuals must be a certified athletic trainer. ${ }^{13,18}$

10. Competencies- The competencies will provide educational program personnel with the knowledge and skills to be mastered by students in an entry-level athletic training educational program. They also serve as a guide for the development of educational programs and learning experiences leading to a student's eligibility to take the Board of Certification examination. ${ }^{18}$

11. Direct Supervision- Supervision of the athletic training student during clinical experience. The ACI and or CI must be physically present and have the ability to intervene on behalf of the athletic training student and the patient. ${ }^{18}$

12. Learning over time- The process by which professional knowledge and skills are learned and evaluated. This process involves the initial formal instruction and evaluation of that knowledge and skill, followed by a time of sufficient length to allow for practice and internalization of the information/skill, and then a subsequent re-evaluation of that information/skill in a clinical (actual or simulated) setting. ${ }^{22}$

13. Mentoring- No definition universally accepted but the goal is to enhance an individual's development of a professional role by way of relationship with a more experienced individual. ${ }^{15,17,23}$

14. Novice Approved Clinical Instructor- A certified athletic trainer who has been certified for at least one year, and has one to three years of clinical experience, and has also undergone ACI training. ${ }^{16,24,46}$

15. Proficiencies- The intent of a Clinical Proficiency is to capture the essence of learning over time by documenting a student's progression from cognitive competence and psychomotor skill performance through supervised clinical application as evidenced by the integration of decision making and critical thinking as measured by the Clinical Proficiency. ${ }^{18}$ 
16. Questionnaire- A series of questions regarding the research topic which will be answered by the selected population of novice graduate assistant approved clinical instructors.

\section{Limitations}

1. The participants will be limited to ATCs who have recently had ACI training.

2. The participants will only have had one to three years of clinical experience.

3. Interaction and selection biases - an external validity threat when a group is selected on a specific characteristic then it may only be generalizable to that group.

Significance of the Study

There is existing research conducted on what good qualities and personality traits an ACI should have but limited research has been conducted with regards to if an ACI feels that the training provided has given the qualities and confidence that is required to teach, evaluate and supervise ATS. Ascertaining this information is important because ACIs are molding future ATCs. If ACIs have prepared ATSs then they will become better ATCs ensuring the advancement of athletic training as a profession.

Furthermore, it is imperative to know how ATCs are feeling about becoming novice ACIs and if they feel adequately prepared after completion of the ACI training course. "The students we supervise will become ATCs, and an assessment of the quality of that supervision might help future supervisors deliver better clinical experiences to students. ${ }^{, 25}$ This study will not only benefit the novice ACIs but the ATSs as well. It is understood that student's clinical education is an important component in athletic training education but the mentoring skills developed by training of novice ACIs has not been proven to be adequately effective. Gaining a better understanding of how novice ACIs perceive the training sessions to have helped them could reveal valuable information which could be used to improve future training sessions. This 
information, once obtained, should be published in journal articles so that all athletic trainers and ATSs are able to view it and learn from past mistakes. Ultimately the results from the current study could be used to improve ACIs and novice ACIs ability to teach, evaluate and supervise ATSs which will inevitably improve the quality of ATCs entering the workforce. 


\section{APPENDIX B}

\section{LITERATURE REVIEW}

Introduction

Athletic training education is a subject that has been discussed and researched throughout the athletic training community. Approved clinical instructor training seminars are a recent addition to the standards that have been instituted for ATCs to be approved to clinically instruct, evaluate and supervise ATSs. It is believed by most medical professionals that novice ACIs are not experienced enough to be effective educators of students under their guidance. Although some studies have investigated novice clinical instructors, this topic is not thoroughly investigated. Evaluating whether novice ACIs believe that the training they have received is adequate enough to feel confident in the role as ACI to athletic training students may be an important tool in deciding what changes should be made so that the educational community of athletic training will be pleased with novice ACIs performance. First, the following literature will flow as follows: a history of athletic training education, understanding of who an ACI is and the role in the ATSs education will be discussed. Second, the importance of choosing the correct ACI and their ability to evaluate the ACIs performance will be included. Forth, current training consistency for ACIs in the athletic training profession and a review of the training consistency for other medical fields such as physical therapy, radiology, and nursing. Finally, the perception of ACI training in athletic training will be explained.

History of Athletic Training

In 1956, the National Athletic Trainers' Association (NATA) Board of Directors appointed an NATA Committee on gaining recognition. The main focus was on professional advancement, "to study avenues through which the professionalization of athletic training could 
be enhanced." ${ }^{26}$ The NATA approved the development of the first athletic training curriculum model of athletic training education in 1956. The curriculum was based on classes that already existed in a four-year university or college and had two main areas of importance. Included in these areas were concentrations in the departments of physical education and health. "The first area of importance was inclusion of classes that would help the students obtain secondary-level teaching credentials due to the high demand for athletic trainers at the secondary school level. This would make the athletic trainer more marketable with teaching credentials in the field of physical education or health. The second area of importance was to include classes that were prerequisites for entrance into physical therapy schools. This would allow the athletic trainer to further educational knowledge, improve professional growth, as well as make the individual more employable."16

As athletic training started to become recognized as a specific body of knowledge more emphasis was placed on desired learning outcomes. Around the 1970's NATA formed a list of "objectives that identified desired learning outcomes forATSs." ${ }^{30}$ It was reported in Harrelson's ${ }^{27}$ study that most ATSs tend to prefer hands on learning experiences and that this has been an indicator of success. ${ }^{27}$ Over time it became more understood that students needed to be involved with patients for a better education. This period provided athletic training with the greatest growth in educational and clinical programs and the NATA Certification Committee administered the first national certification examination. ${ }^{26}$ Both the implementation of the certification exam and the recognition of the first undergraduate athletic training programs history advanced the professionalism of athletic training, which later led to community recognition. 
While the number of athletic training programs were increasing the number of ATSs was also increasing as well. The increase in more ATSs, decreased the need to take physical therapy prerequisites and provided more of a focus on course work in the field of athletic training. It was now felt that a teaching degree in physical education or health was actually limiting the student's chance of obtaining employment at the secondary level due to the number of students going into the field of athletic training. ${ }^{16}$

It was not until the 1970's that formal clinical education guidelines were implemented. Objectives and competency checklists were created to guide the clinical education process. There were two routes to be eligible to sit for the Board of Certification exam. One was to complete 600 to 800 clinical hours in an approved curriculum program or 1800 total clinical hours in the internship route.

Early in the 1980's, it was proposed that athletic training should become a major in colleges/ universities. On July 1, 1986, the NATA Board of Directors required an approved athletic training curriculum major to be implemented in all NATA approved ATEPs and was later extended to 1990. Once the major was created, the Guidelines for Development and Implementation of NATA Approved Undergraduate Athletic Training Education Programs were developed as the standards for the undergraduate athletic training programs. ${ }^{26}$

In the 1990's the NATA Board of Directors decided to gain recognition from the American Medical Association (AMA) in order to seek accreditation of the entry level athletic training programs by the Committee on Allied Health Education and Accreditation (CAHEA). For the first time the AMA formally recognized athletic training as an allied health care profession. Once the profession was recognized by the AMA, the accrediting organization for the undergraduate programs changed from the NATAPEC to the AMA Committee on Allied Health 
Education and Accreditation (CAHEA) ${ }^{26}$ A review committee was also formed for entry-level allied health education programs. ${ }^{26}$ "This change was made to gain the benefits of standardized education program requirements and external peer review by a highly regarded, specialized accreditation agency. In 1991, the Guidelines for Development and Implementation of NATA Approved Undergraduate Athletic Training Education Programs were replaced with the Essentials and Guidelines for an Accredited Educational Program for the Athletic Trainer to meet the standards of the AMA continuing medical education."

In 2004 the internship route was eliminated leaving the only option for certification to attend a college/university that had an accredited program. Currently, to sit for the certification exam, an ATS must attend and graduate from a CAATE accredited ATEP. ${ }^{18}$ Clinical education guidelines created by CAATE stated that clinical experiences must be under the direct supervision of an approved clinical instructor (ACI) or clinical instructor (CI) in the appropriate clinical setting. The ACI must have the ability to intervene during patient care if necessary to provide the student with consistent learning. The $\mathrm{ACI}$ and student ratio must also ensure effective education and should not exceed eight to one. These standards must be met to ensure ATSs will get "opportunities to practice and integrate the cognitive learning, with the associated psychomotor skills requirements of the profession, to develop entry-level clinical proficiency and professional behavior as an ATC as defined by the NATA Educational Competencies. ${ }^{28}$ With the new clinical requirement for the ATSs in their clinical experience, the demand for qualified clinical instructors to educate the students has increased. Approved clinical instructors have the difficult task of handling patient care as well as ATSs education.

What is an Approved Clinical Instructor?

An approved clinical instructor is one of the main influences of an ATS's educational 
career. ${ }^{13}$ The relationship that a student has with an ACI will shape the educational outcomes and result in either good or poor athlete care. In 2001, the Commission on Accreditation of Allied Health Education Programs (CAAHEP) included a recommendation that ATCs associated with educational programs complete professional training for the role as clinical instructors. The National Athletic Trainers' Association Education Council (NATAEC) decided that clinical instructor educator (CIE) seminars should be implemented with the main goal being to equip program directors and clinical education coordinators with the information and resources to serve as CIEs at their institutions. The CIEs would then train ACIs to effectively teach and evaluate athletic training clinical proficiencies and supervise ATSs. ${ }^{13}$

In order to be considered an ACI an ATC has to be certified by the Board of Certification (BOC) for a minimum of one year and must have undergone ACI training by the respective $\mathrm{CIE}$ at that institution. Upon completion of that training the ACI would be allowed to supervise ATSs and complete clinical proficiencies with the students. ACIs must always have a professional attitude while in the athletic training room, since they are serving as role models to students and will shape the future of athletic training by educating future ATCs. According to Giordano, ${ }^{29}$ Laurent and Weidner describe an ACI as "a person who provides direct supervision and instruction to students in the clinical aspect of athletic training education." ${ }^{29}$ ACIs have the difficult task of combining classroom knowledge and skills. ${ }^{29}$ Moreover since students spend a great deal of time in the classroom learning theories and book knowledge, ACIs are expected to help ATSs put that knowledge to clinical practice within the clinical setting. Essentially both ATCs and program directors (PDs) need to have a clear, working definition of the roles and responsibilities of an ACI in order to be effective educators. ${ }^{29}$ 
In a literature review conducted by Weidner and Henning ${ }^{19}$ information was taken from the Educational Resources Information Center from historical textbooks on medical education. By gathering this information they hoped to be able to understand the way in which clinical education has formed and help to shape the future of athletic training education. Weidner and Henning ${ }^{19}$ reported that in the early $19^{\text {th }}$ century there was a lack of consistency between clinical instructors in the medical field. As a result it was decided by a committee that it was mandatory to work with a clinical instructor and in a hospital to acquire knowledge and experience. This process failed to involve students in any hands on work and only left them to observe.

Weidner and Henning ${ }^{19}$ also remarked on future directions in athletic training, they said that a clinical instructor is one of the most important aspects of the student's education. It is also mentioned that since ATSs were being discouraged from being thought of as more of a work force than students, clinical instructors were less concerned with making sure students understood all clinical care adequately. Peer education is thought to be an upcoming way that students will learn clinical skills. ${ }^{19}$ Approved clinical instructors must reevaluate their teaching procedures as athletic training evolves. Styles and preferences of learning are different and change over time. Understanding different learning styles can be advantageous and ACIs need to be aware of this and be able to adapt over time..$^{12,27,30}$ The latest learning and teaching styles are not material that is covered in an undergraduate education for athletic training. Students who graduate and decided to attend a graduate school or to work for an undergraduate program may by necessity become an ACI for that institution. This would result in novice ACIs not being fully prepared to instruct ATS.

Novice Approved Clinical Instructors

A novice $\mathrm{ACI}$ is an $\mathrm{ATC}$ who has recently undergone the $\mathrm{ACI}$ training at the institution 
where they will be supervising ATS. Pircher ${ }^{16}$ defines a novice graduate assistant ACI as a certified athletic trainer who has been certified for at least one year, a graduate assistant, and has one to three years of clinical experience. Stemmans ${ }^{46}$ defines a novice clinical instructor as someone who has less then one year of clinical instructor experience. For the purposes of this study and according to the operational definitions, a novice ACI is an ATC who has been certified for at least one year, and has one to three years of clinical experience, and has also undergone ACI training.

Novice ACIs lack the experience that an expert ACI possesses. Unsworth ${ }^{31}$ stated that experts possess a better base knowledge than novices do and this will allow them to use recollections from past experiences in current situations. Novice medical professionals tend to use more irrelevant information in the decision making process then experts and seem to recall critical cues less frequently then experts. Novices tend to confirm their hypothesis by collecting more information rather then by testing it to disprove it. An expert can solve a clinical problem faster then novices as well as they have generally better clinical reasoning skills. Another main difference between a novice and an expert is that experts seem to take more time and focus on the patient and their personal differences with an injury. A novice will focus more on solving the problem and has little focus on the patient as a whole. This shows that with expertise better communications skills are developed. ${ }^{31}$ Consequently, if novice ACIs communication skills are not fully developed then interactions with students will be less productive considering a student is even more novice than the ACI acting as a supervisor. Unsworth ${ }^{31}$ continued by stating that the greatest difference between an expert and a novice is clinical reasoning skills. The time frame in which a novice will transition into an expert in unknown and different for each person. ${ }^{31}$ 
Wilcoxson ${ }^{49}$ agrees that novice ACIs are not prepared to provide excellent clinical instruction to ATS. Novice ACIs are more focused on their own professional roles and not ready to fully focus on the educational needs of the student. Novice ACIs are involved in the process of developing their own confidence and decision making abilities while establishing rapport with coaches, student athletes and staff. In addition to the above mentioned issues, Wilcoxson ${ }^{49}$ included that novice ACIs must also become familiar with the didactic and clinical progression of the student before being able to serve as an effective clinical instructor. ${ }^{49}$

Another concern with novice ACIs is their ability to recognize or distinguish between a "teaching patient" and a "nonteaching patient" which would ultimately hinder the ATS learning opportunities. ${ }^{46}$ Also of concern is the finding that graduate assistant (GA) ATCs serving as ACIs experienced role incompetence. ${ }^{39}$ This means that ATCs are lacking the abilities to be able to fulfill there roles as ATC and ACI. Graduate assistants are filling these new positions and this may not be an ideal situation. Graduate students are often newly certified and have minimal practical experience ${ }^{47}$ Henning ${ }^{39}$ examined stress in GA ACIs and reported even though only 1.5 years of work was performed, time management skills, patient care, clinical education, administrative work and personal academics all showed to be lacking and poor. ${ }^{39}$ Thus, the question has been raised by other professions, is one year of clinical education enough to work as an $\mathrm{ACI}$ ?

Medical educators and other fields such as nursing have suggested that clinical education should be conducted by practitioners with several years of experience. For GAs to take on teaching roles and responsibilities will be detrimental to the quality of teaching, supervision and evaluation skills because of the lack of professional experience. ${ }^{47}$ Having appropriate ACIs typically require experience to perform well and too often ACIs are left to develop these skills 
individually. ${ }^{47}$ The concept of ACI training was not originally designed to reduce the risk of role strain but it could be of importance to reexamine how ACIs are prepared for these roles. Henning and Weidner ${ }^{39}$ suggested that it may be beneficial to conduct more frequent continuing education training sessions to reinforce concepts of effective clinical education and for ACIs to seek feedback on current supervisory practices. ${ }^{39}$ Wilcoxson ${ }^{49}$ agrees that GAs are typically both novice clinicians and new to an institution, and as a result it would be very challenging for them to provide excellent clinical instruction even in the second year of their assistantship. Graduate assistants are building confidence, decision making skills and rapport during the one or two years of their assistantship. Due to this the GA will have "difficulty recognizing and relinquishing clinical experiences that are necessary for junior and senior ATS to build confidence and relationships in these same areas." ${ }^{, 49}$ However, an ATS will tend to approach a GA before they would a staff member with questions or assistance. This may be due to the fact that they are not as intimidating and still seen as a student. Wilcoxson ${ }^{49}$ found that novice ACIs have a lot to offer an ATS since they are still excited about the profession, have professional knowledge and skills and are eager to work with students. Novice ATCs, ACIs and GAs are vital to senior students who are currently trying to determine their next professional or educational steps because they have recently accomplished that. For these reasons novice ACIs are important in ATS clinical education but need the proper preparation. ${ }^{49}$ Selecting excellent ACIs and evaluating them to ensure they are continuing to grow in there profession is vital in a successful institution.

Selection and Evaluation of Approved Clinical Instructors

As previously stated one of the key components of an ATS education is the clinical setting and the quality of the ACI. Many ATCs have admitted that being an ACI does take up a 
lot of their daily time and responsibilities. Athletic trainers chosen for the position of ACI are expected to provide learning experiences that are beneficial and demonstrate to students appropriate behaviors. A vital aspect of good clinical education is selecting qualified athletic trainers to be ACIs and evaluating them to ensure they are quality ACIs.

Lauber $^{21}$ conducted a study to investigate the importance of clinical instructor behaviors to program directors and ACIs. The author found that the results from the study should be used in developing an evaluation tool for ACIs that would identify if these important behaviors are in fact being implemented. The tool was made up of information consisting of instructional behaviors which included explaining information clearly to students, demonstrating, practice opportunities, and answering questions adequately. Interpersonal behaviors included in this tool were allowing an expression of opinions, encouragement, availability, interest in student performance and a demonstration of respect for the student. The evaluation portion of Lauber's ${ }^{21}$ tool included tactful interactions while correcting student behavior, constructive feedback, fairness, and defines the expectations of the student. Also incorporated into the tool were professional and personal categories. Information in the professional category included demonstrating interest in athlete care, demonstrating clinical knowledge, accepting responsibility for own actions, and acting as a professional role model. Personal characteristics included were having a sense of humor, honesty, flexibility while working with students, patience, and enthusiasm. ${ }^{21}$ By using this tool, potential problems with clinical education could be identified. This would allow for ACIs to have feedback on their performance and may find it useful for self evaluation and development, allowing for an ACI to understand what their teaching behaviors are and how to further improve upon their weaknesses and strengths. This tool may also be helpful in the selection of ACIs for institutions. This information can become an objective 
measure when selecting ATCs who demonstrate an interest in being an ACI. ${ }^{21}$

It is important that educational expectations be held in high regard and be investigated and established by members of the athletic training profession rather then borrowing ideas and practices from other professions. In 2004, Weidner and Henning ${ }^{32}$ found that there was no "research-based and peer reviewed" ACI standard or instructions on how to select and evaluate ACIs. Guidelines are needed to have a more standardized and official approach to clinical education in athletic training. ACIs must be held accountable for teaching, evaluating and documenting clinical proficiencies. Weidner and Henning ${ }^{32}$ selected twenty program directors (PDs) and provided them with 9 initial potential standards and 76 associated criteria gathered from other medical fields. They were then asked to brainstorm and to list any information that they deemed fit to use as a measuring standard as well as any additional information they believed should be included. Using a Likert scale each PD was next asked to rate the information collected. The third round consisted of a questionnaire that was used on the information gathered in the second round and a consensus was reached as to the "essential standards and criteria needed to select, train, and evaluate ACIs.",32

The standards were divided into different categories, the first being legal and ethical behaviors. Abiding by the NATA Code of Ethics and complying with federal, state and local laws regulations will affect the ATC's role as ACI. Any irresponsible behaviors by the ACI would provide poor examples for ATS. Communication skills were included in this study as well. Communication is essential for a successful learning environment. Each situation will need a different style of communication in order to be effective. Approved clinical instructors that are selected to work with students must have efficient communication skills in order to supervise effectively. Interpersonal relationships are crucial to making students feel valued and 
respected. Approved clinical instruction should enter each relationship with positive professional and mentoring attitudes. Another vital aspect of the standards are good instructional skills. Approved clinical instruction should be knowledgeable in basic educational principles regarding teaching. Due to the fact that this is not part of the CAATE curriculum then it needs to be included in the ACI training prior to ACIs supervising students.

Approved clinical instructors also need to be proficient in the areas of their field. They should be aware of the student's current level of knowledge to be able to understand what specific areas need to be covered more thoroughly. Approved clinical instructors most importantly must be able to "synthesize their knowledge to develop content-specific pedagogy". ${ }^{32}$ When content specific knowledge and teaching methods are combined into specific instruction for ATS there is new knowledge resulting for the ACI; they are actually learning through teaching ATS. It is the knowledge developed through teaching that separates ACIs from someone who is just an expert in a certain topic. ${ }^{32}$

Supervisory and administrative skills were deemed important skills for an ACI to possess. ${ }^{32,33}$ Being readily available to students is of high importance but it is also critical to student learning that feedback does not become hindering. Allowing for the student to be able to make decisions is important for professional growth and confidence. An ACIs administrative skills are also of importance.

Program directors and athletic directors expect the ATC to be proficient and knowledgeable in administrative work. Being able to manage their time and delegate tasks to complete what needs to be done is a crucial skill. Evaluations of student performance are one of the most important roles an ACI will play. Students need to be informed of strengths and weaknesses in order to improve. Approved clinical instructors need to actually be aware of 
student's skills and base the evaluation of performance rather then personal bias. ${ }^{32}$

Weidner and Henning ${ }^{13}$ also decided it was appropriate to assess the applicability of the standards they set to evaluate and select ACIs. The found that the results indicated their previous research was important and applicable to ACIs in various clinical settings. These standards are said to be appropriate for CIEs to use for the selection, training, and evaluation of ACIs. The ACIs can then in return use these standards to self critique what their educational practices are. ${ }^{13}$ Current Approved Clinical Instructor Training Consistency

The current ACI training has a "learning over time" concept that includes the demonstration of systematic progression through the cognitive and psychomotor categorization within different background environments. The assessment of learning over time is built around multiple indicators and sources of evidence such as observations, performance samples, and test procedures. It is the ACIs responsibility to implement learning over time so that the ATS can integrate all learning in a critical manner. Approved clinical instructors must also be aware of the educational background of each ATS and that each evaluation is based on information that has been covered in class. Progression will be mastered by observation, acquisition, and clinical proficiency demonstration and application. Observation involves little to no hands on experience. Acquisition is the initial education and introduction to the competencies which is mostly accomplished in lecture. Competence is the ability of the ATS to practice and show mastery of each individual skill. ${ }^{34}$

The method to which someone obtains information and then uses the information to learn is called their learning style. Brower ${ }^{50}$ found that by being aware of students learning styles educators can then aid in appropriate learning experiences. There are different learning styles that ACIs must be aware of. This will allow them to provide stimuli to each student at some 
level. The learning styles have been grouped into two categories. The first style is called "sensory" which is a visual, auditory, and kinesthetic style dealing with the way a student gathers information. For this style of learning the student will not need much oral explanation. The second style is called "expressive" and this is dealing with the environment in which a student does the most efficient work and learning. "Expressive" students are more oral and written learners. ${ }^{34}$ Brower ${ }^{50}$ found that in the medical community students prefer a more hands on learning environment.

Clinical proficiencies assess an ATSs ability to put to work all aspects of a particular situation to solve a problem. The combined skills evaluations are intended to assess the student's ability to integrate all cognitive, psychomotor and affective traits with decision making and problem solving skills. The clinical proficiencies will be evaluated by scenarios and simulations in the clinical setting. The evaluation will be deemed one of the three; developing, proficient, or mastery of subject matter. ${ }^{34}$

Teaching clinical proficiencies requires a multidimensional approach. The ATS has the responsibility to practice skills and learn knowledge but the ACI should be aware of four dimensions for ideal teaching. The first is content, this refers to the knowledge a student will receive from an ACI. Not only does this encompass book and theory knowledge but also how to use professional strategies, tricks and ACI experience to help the student achieve this. Teaching methods that are used to integrate the student into the profession must take into account the current level of knowledge, social and physical environment to allow the student to react and respond to the situation. Sequencing deals with the acquiring, integrating, and use of knowledge. An ACI will want to make it harder as the student progresses and apply the same knowledge to different situations. Sociology is when the ACI allows enough time for the ATS to develop 
interaction and professional practice. ${ }^{34}$ Due to the fact that ACI workshops are a new concept in athletic training, it would be beneficial to evaluate the effectiveness of other medical and allied health professions in training ACIs to teach and evaluate students.

ACI responsibilities consist of demonstrating appropriate clinical skills and knowledge. An ACI must have legal and ethical behavior to be a good role model for ATS following the NATA code of ethics and maintain good standings with the NATA and the BOC. Good communications skills include active listening, adaptation to student learning styles, positive feedback, and tact with negative feedback with clear explanation of the problems. ACIs must be ready to be available to students and provide answers and feedback when questioned. Instructional skills must be clear with an encouragement of critical thinking and problem solving. A very important task of an ACI is to provide a clear and objective evaluation of student performance and maintain an appropriate professional relationship with students. ${ }^{34}$ Training of Approved Clinical Instructors in Other Medical and Allied Health Fields

Research in nursing clinical education has focused on clinical instructor training strategies to improve the clinical instructors questioning skills. ${ }^{35}$ Training sessions appeared to be helpful but additional training would be required as well. In one particular study the control group had disconcerting outcomes perhaps based on actual representation of clinical instructor's abilities to incorporate questioning for higher-level processing. ${ }^{35}$ Results revealed that two distinct methods of question asking can help ATSs acquire technical athletic training knowledge and clinical reasoning skills. ${ }^{35}$ Strategic questioning helped the students form a basis for problem solving skills and ultimately helped them with clinical reasoning skills and clinical thinking skills. Nonstrategic questioning will not build upon base knowledge for understanding complex concepts. Phrasing appropriate questions while teaching students is a method that is not taught 
in the ACI workshops yet nursing literature deems it important in clinical education.

Midwifery conducted research on clinical practice and role modeling as a source of training. Armstrong ${ }^{36}$ states that midwifery education should be based upon clinical practices. The teaching should be one on one teaching through role modeling. Although this would be very beneficial, in athletic training it is unrealistic due to time restraints. Armstrong ${ }^{36}$ believes that role modeling is the means by which students discover knowledge. Students tend to learn through observation and do not realize that they are doing this. To effectively facilitate learning, role modeling cannot be the only concept of teaching used. Role modeling needs to incorporate additional teaching strategies that were not discussed in this particular article. Furthermore, it has also been noticed that students are more inclined to ask questions during clinical practice and one on one role modeling. Armstrong ${ }^{36}$ also noted that students are able to observe how one would interact with the patient, prioritize, time manage and deal with certain challenging situations. ${ }^{36}$

Midwifery clinical educators believe that it is important to use a variety of teaching methods to enhance learning because teaching can be extremely complex. ${ }^{36}$ Midwifery clinical instructors use the idea of behavioralism in their clinical teaching. There is some debate though about the appropriateness and ethical complications surrounding this type of practice.

Behavioralism is a type of operant conditioning where a student will receive an award for correct clinical practice. Positive reinforcement accompanies the reward and the two result in that correct response being repeated by the student. ${ }^{36}$

Some of the main characteristics which a midwifery clinical instructor should possess include enthusiasm, professionally organized, caring, self-confidence, knowledge, good communication skills. The ideas of clinical instruction in midwifery education and those of 
athletic training education seem to be very similar. Incorporating information from many of the medical professions on clinical education may ensure a more well rounded and thorough system for clinical education. ${ }^{36}$

In physical therapy, clinical education constitutes a great deal of the academic curriculum as well. ${ }^{37}$ Jarski ${ }^{37}$ states that "clinical teaching involves exposing a student to conditions, usually in an active patient setting, where the probability of learning clinical information is high."${ }^{37}$ The behaviors and attitudes of all involved in the clinical setting where teaching is taking place affects the learning outcomes either positively or negatively. Students are leaning behaviors that influence their lifetime professional performance therefore, improvements of the quality of clinical education will improve the future of the profession. ${ }^{37}$ Jarski continues by stating that "effective clinical instruction in these settings is believed to require a unique subset of teaching skills, and specific teaching behaviors should be identified and evaluated. ${ }^{, 37}$ One reason is the promotion of a helpful and positive learning experience which will ensure proper skills and behaviors needed for a student's future in the profession. The researcher also recognized that most clinical instructors do not have a formal educational preparation course and have been selected for their position because of clinical skills and not because of teaching abilities. Physical therapy students found that the most helpful behaviors consisted of communication skills, professional skills, interpersonal skills and andragogic skills. Even though there were many helpful behaviors described in the research, teaching skills were considered most important in students learning. ${ }^{37}$

In academic programs like physical therapy (PT) the students are in constant contact with the ACIs and they play a responsible and influential role in the professional and social development of PT students. Even so, there is a insufficient amount of published literature 
describing the qualifications and credentials of these individuals. ${ }^{38}$ Giles $^{38}$ conducted a study to identify the qualifications of becoming a clinical instuructor in the PT clinical setting. Pysical therapist ACIs are expected to be able to adjust their teaching styles to adapt to differences in student learning ablilities as well as assess the students skills and compare them to the standards of an entry level ATC compared to the programs standards. Physical therapists are reccommended to have 1 year of clinical experience by the American Physical Therapist Association (APTA) before becoming an ACI. ${ }^{38}$ In the study, Giles ${ }^{38}$ found that less then $25 \%$ of the population surveyed had a formal APTA Clinical Instructor and Credentialing Program. One PT that was surveyed reported there is a need for a workshop for CIs serving PT students, and continued that the attempt to produce quality behaviors in the current ACIs was unsuccessful. Giles ${ }^{38}$ stated that there should be a change in the future regarding the credentialling of PTs as ACIs and that continued data collection should take place in order to assess if there is change in the number of credentialed ACIs in the field of PT. ${ }^{38}$

Radiology ACIs have the same ideas and conceptions that the athletic training field has on the importance of an ACI and the affect they will have on clinical education. In radiology they believe that ACIs have the responsibility to teach and evaluate students but that they do not always have the appropriate preparation for this. ${ }^{29}$ In radiology the ACIs are chosen based on clinical skills rather then teaching abilities and this is the same as in athletic training. The research that has been conducted stated the need for ACIs to be more available to students and encouraging. Furthermore, ACIs need to have good communications skills and be able to have a variety of teaching skills to be able to adapt to different learning styles. Characteristics that were found to be effective in radiology clinical education are similar with those of athletic training, communication skills, ability to teach and at the same time provide patient care are three of the 
main characteristics. ${ }^{29}$ Some of the negative characteristics of behaviors were also identified in athletic training clinical education, intimidation, criticism, excessive supervision and negative responses to student questions. In the clinical setting it was found that the student's performance was directly related to how much time the student spent with the ACI. One of the most important aspects of radiology clinical education is communication and corporation between the program and the clinical site. The same is true for athletic training education. Proper training of clinical instructors can reduce stressors and eliminate mistreatment as well as understanding the different learning styles that exist in the student population. ${ }^{29}$

By looking at other medical professions common trends and differences in the training of ACIs are noted. Due to the fact that athletic training as a profession is much less mature then other medical professions, these should be used as a template in training ACIs by using both failures and successes. Currently there are not many studies that look directly at the training of ACIs in athletic training. However, there are studies that provide insight into how ACIs are functioning in the clinical setting. Perceptions of Approved Clinical Instructor Supervision in Athletic Training With a change in athletic training clinical education, ACIs have been placed into different roles. There was evidence of role strain among ATCs who were balancing clinical education with patient care. ${ }^{39}$ It is a goal of most ATCs to accommodate all the expectations placed on them but in reality this is a difficult task. Attempting a task such as this can lead some to experience role strain. It is suggested that an ATC who tries to be a clinical educator, health care provider and administrator may not be able to fulfill each role; unfortunately the role that suffers most often is being a clinical educator to athletic training students. ${ }^{39}$ It is likely that as workload increased for an ACI that the role strain would increase. ${ }^{39}$ As a result effective coping 
strategies should be implemented in ACI training to avoid the risk of burnout, which would untimely affect the students learning abilities.

The clinical experience is a major portion of an ATS's athletic training education. ${ }^{17,32}$ The ACI's influence on this experience is well recognized and responsibilities are increasing. Curtis ${ }^{17}$ conducted a study to investigate helpful and hindering ACI characteristics from the ATS's perspective. They felt it was important to know and understand how ATS view ACI supervision and teaching abilities to recognize if there is a potential problem. Since ACI supervising behaviors affect the student learning experience it should be included in the training of ACIs what the helpful and hindering characteristics are when supervising ATSs. ${ }^{17}$ Mentoring behaviors such as explanation, demonstration and constructive feedback were regarded as highly effective behaviors. ${ }^{14,17,40}$

Mentoring is a "strategy for facilitating the professional growth and development of students while they are socialized into a discipline". ${ }^{23}$ This is typically achieved by a relationship with a more experienced person. ${ }^{15,23}$ It is a process where relying on advice to guide learning, while helping to build and grow in a profession. Mentoring can influence how one is prepared to develop values, skills, knowledge and attitudes in a career. Pitney ${ }^{23}$ found that students almost always will identify their mentoring relationship with their immediate ACI. Three aspects of mentoring were noted in this particular study, accessibility, approachability and protégé initiative. In order for an ACI to be a good mentor accessibility to students is important. ${ }^{23,33}$ Mentors need to balance time between sports assignments and ATS in order to provide students with the supervision they need. Students are more likely to approach ACIs who do not demoralize them and treat them with respect. ${ }^{14,23,40}$ Students also recognized that mentors need to help them understand what they need to do in order to improve skills and understand how to improve critical thinking and problem solving skills. ${ }^{23,40}$

Mentoring has been well documented as successful in other professions as noted in the such as education, business, medicine and nursing literature. ${ }^{15}$ Athletic training education has also 
recognized this and has found that mentoring may be confused with role modeling. "Role modeling is thought to be more of a passive process, whereby students take on the values and behaviors of a clinical instructor (CI) by trying to emulate what they observe. Mentoring, on the other hand, requires active involvement by students as they engage in a personal relationship with an experienced individual to learn about the profession and promote professional socialization., ${ }^{23}$ This is important to remember because a more productive learning environment and relationship will evolve from mentoring where students can interact with a more experienced professional rather then emulate what they think they are observing. ${ }^{23}$ Novice ACIs need to remember that everything they do while working may be closely observed and reflected upon by ATS. ${ }^{15,40}$ Conversely, Pitney ${ }^{15}$ had found in a similar study that students who were surveyed responded with a slightly above normal response with respect to mentors needing to be significantly more experienced then a protégé. He concluded that it was not clear whether a mentor needed to be significantly more experienced then a protégé to be effective ${ }^{15}$

Platt ${ }^{41}$ wrote that professional skills and abilities are refined in clinical-education. As others have previously stated, clinical education relies heavily on clinical instructors and the knowledge, leadership skills, supervising and mentoring abilities they possess. Due to ATS's different learning styles and emotional behaviors it is important for ACIs to be able to change teaching styles and leadership skills to adapt to students needs in different situations. Those who will be educating ATS need to improve and hone leadership skills and styles. ${ }^{37,41}$ The main purpose of Platt's ${ }^{41}$ research was to devise a situational leadership model for future ACIs to use in clinical educational settings. Leadership has many different definitions but is best defined "as the ability to induce others to take actions toward a common aspiration., ${ }^{, 41}$ To be a good leader you must know who you are leading, how others perceive your leadership styles and be aware of 
your own style and how it suits you. Being aware of whom you are and your leadership style includes knowing the students you are teaching, the level of knowledge they have and to be able to change when mental abilities and emotional abilities change. As the ATS's level of readiness to participate changes, so should the ACIs leadership strategy.

Leadership leads to increased productivity and a better work environment. It has been shown to reduce burnout and with improved leadership there is an improved employee satisfaction. Leaders need to have the ability to influence others in order to complete and reach goals. Athletic trainers influence the people with whom they work with everyday. ${ }^{42}$ Working with athletes or ATS are two situations in which leadership skills are needed. Leadership is very important in athletic training for this reason and effective behaviors should be recognized and mimicked. In Laurents ${ }^{42}$ study on leadership, an athletic trainer will use skills such as modeling the way one should act and enabling other to act more then most other professions. He found that most ATCs seemed to be prepared for their leadership role but also noted that continuing education can prepare people for leadership as well. ${ }^{42}$

Professionalism is something that ATCs hope will be carried through the generations of ATCs to come. It is very important not only as a community but for other professions to see as well. It is important for graduates to see athletic training as a profession and not just a job. ${ }^{43}$ Clinical experiences offer students the time to execute knowledge obtained in the classroom and use it in real life situations allowing students to be more sensitive to patients and competent while performing patient care practices. ${ }^{43,44}$ This will then ensure successful practitioners but will not guarantee that they will become competent professionals. ${ }^{45}$ It is believed that many of the professional characteristics that are required as an ATC are not easily taught and must be learned through experience and student encounters. Instead of standing in front of a classroom 
and showing the students step by step procedures on how to use a device, readings would be assigned followed by a discussion. $\mathrm{Craig}^{43}$ believed that this provides a sense of autonomy, responsibility and creates their own "blueprint" which is called learner-centered education.

It is suggested that teaching professionalism in the classroom creates further knowledge on an academic subject and does not create professionals. "Within each ATEP, a variety of ACIs commonly serve as role models for students. Each of these ACIs will naturally demonstrate professionalism differently. Thus, regardless of presentation in the classroom, student learning of professionalism will fluctuate with clinical placements. This fluctuation may be decreased to some degree by the equal rotation of students through all clinical sites. Thus, careful selection of the most professional ACIs is critical for optimal development of professionalism in students." ${ }^{, 43}$ Approved clinical instructors are the mentors for professionalism to their students. With many of the ACIs being novice GAs, lack of ACI training can affect the way an ATS forms professional behaviors.

If asked most students will state that the majority of their education and skills have come from clinical education. ${ }^{13,14,15,17}$ Given that, it is important for program directors and CIEs to appropriately select, train and evaluate ACIs. When ACIs are more prepared and knowledgeable about student learning techniques then it will allow for students to learn in accordance the purpose and requirements of accreditation, especially regarding the quality of athletic training clinical education. ${ }^{13,17}$ Quality of athletic training education relies heavily on the quality of the supervision received in the athletic training room setting. It has been previously researched that having good athletic training skills does not ensure quality teaching of those skills. Teaching skills are not something that is included in undergraduate education and therefore ACI training must be administered. What has not been extensively researched is whether training is adequate 
for novice ACIs to feel confident and prepared to supervise, teach and evaluate ATS.

Summary

The vitality of the athletic training profession largely depends on the quality of the education provided. ${ }^{48}$ Student education widely depends upon the ACI involvement and it is crucial for novice ACIs who have been shown to be incompetent and lack teaching knowledge have effective and adequate ACI training. Other medical fields feel that ACIs should be someone with experience and that novice clinicians are not qualified for this job. In athletic training novice ACIs are inevitable and therefore the necessity for quality training in this area is vital. It is obvious then if we are placing novice ATCs and GAs in the position to be ACIs to undergraduate students that the training should be adequate in the opinion of the ATC who is receiving it. ${ }^{48}$ Wilcoxson ${ }^{49}$ asks, where in the athletic curriculum and preparing to challenge the certification examination qualify one to be an ACI? One thought is that we simply teach the way we have be taught. We rely upon our own experiences as a student to direct our methods. Unfortunately this causes an inconsistent education from one student to another. ${ }^{49}$ A thorough look into the thoughts and views of novice ACIs and their feeling about the preparedness to teach evaluate and supervise athletic training student in the clinical setting needs to be implemented for the benefit of athletic training as a whole. 


\section{APPENDIX C}

ADDITIONAL METHODS

Table C1. Cover Letter to Program Directors

\section{Dear Program Director,}

Hello, my name is Amanda Hart. I am a graduate student at West Virginia University, as well as an educational graduate assistant. In order to fulfill the requirements of a master's thesis and complete my Masters of Science in Athletic Training, I am seeking your help to complete a research study entitled "The Perception of Novice Approved Clinical Instructors on their Preparedness as Clinical Educators." This letter is a request for you to provide me with contact information (i.e., e-mail addresses) of approved clinical instructors (ACIs) at your institution who have undergone the ACI training workshop and have been certified for at least one year with three or less years of clinical experience. This information is being solicited as an initial step in data collection for my thesis with the primary investigator Damien Clement, Ph.D., ATC at West Virginia University (Morgantown, WV, USA).

Your involvement in this project will be kept confidential. Your participation in this project is completely voluntary; however, I hope that you will provide me with the requested information since it could be very beneficial in evaluating novice ACI's level of satisfaction with their training. This information could then be used to provide suggestions about improving ACI training. West Virginia University's Institutional Review Board acknowledgement of this study is on file.

Thank you very much for your time. Should you have any questions about this letter or the research project, please feel free to contact Amanda-Jean Hart at ahart7@mix.wvu.edu.

Thank you very much in advance for your help with this project.

Sincerely,

Amanda-Jean Hart 
Dear Approved Clinical Instructor,

This is a request for you to take part in a research project to assess the perceived preparedness of approved clinical instructors (ACIs) once they have completed the ACI training workshop and are asked to teach, supervise and evaluate athletic training students. This thesis is being conducted by Amanda-Jean Hart, ATC a graduate student from West Virginia University's Athletic Training Program under the supervision of Dr. Damien Clement (Assistant Professor; West Virginia University). Your participation in this study will take approximately 20 minutes to complete a 48 item questionnaire.

Your involvement in this study will be kept confidential. You must be 18 years of age or older to participate. I will not ask any information that allows you to be identified as a participant. Your participation in this study is completely voluntary, you do not need to answer any questions you do not wish to answer and you may stop your participation at any time without any penalty. Furthermore, your employment or academic standing will not be effected if you decided to either not participate or withdraw from participating. West Virginia University's Institutional Review Board acknowledgment of this study is on file.

I hope that you will participate in this research project, as it could be very beneficial to the field of athletic training and in understanding how novice ACIs feel their training was in the approved clinical instructor workshops. Thank you very much for your time. Should you have any questions about this letter or this study, please feel free to contact Amanda-Jean Hart at ahart7@mix.wvu.edu.

Thank you once again for your time and help,

Respectfully yours,

Amanda-Jean Hart 
Dear Approved Clinical Instructor,

I would first like to take this opportunity to thank you, for completing the questionnaire assessing the perceived preparedness of approved clinical instructors, if you have already done so. Your participation is deeply appreciated since the number of responses is a key factor in obtaining useful results. If, however, you have not completed the questionnaire I would once again like to request that you participate in this study.

This is a request for you to take part in a research project to assess the perceived preparedness of approved clinical instructors (ACIs) once they have completed the ACI training workshop and are asked to teach, supervise and evaluate athletic training students. This thesis is being conducted by Amanda-Jean Hart, ATC a graduate student from West Virginia University's Athletic Training Program under the supervision of Dr. Damien Clement (Assistant Professor; West Virginia University). Your participation in this study will take approximately 20 minutes to complete a 48 item questionnaire.

Your involvement in this study will be kept confidential. You must be 18 years of age or older to participate. I will not ask any information that allows you to be identified as a participant. Your participation in this study is completely voluntary, you do not need to answer any questions you do not wish to answer and you may stop your participation at any time without any penalty. Furthermore, your employment or academic standing will not be effected if you decided to either not participate or withdraw from participating. West Virginia University's Institutional Review Board acknowledgment of this study is on file.

I hope that you will participate in this research project, as it could be very beneficial to the field of athletic training and in understanding how novice ACIs feel their training was in the approved clinical instructor workshops. Thank you very much for your time. Should you have any questions about this letter or this study, please feel free to contact Amanda-Jean Hart at ahart7@mix.wvu.edu.

Thank you once again for your time and help,

Respectfully yours,

Amanda-Jean Hart 
Table C4. Questionnaire to Novice Graduate Assistant Approved Clinical Instructors

Are you a graduate student?

Yes

No

Are you an Approved Clinical Instructor (ACl)?

Yes

No

How many years have you been an $\mathrm{ACl}$ ?

Less than one year

One year

One to two years

Two years

More than two years

How many years have you been a certified athletic trainer (ATC)?

Less than one year

One year

One to two years

Two years

More than two years

What is your current clinical setting? (the setting in which you spend the most time performing clinical athletic training duties)

College / University

High School Clinic

Outreach

Industrial

Other

How many athletic training students (ATS) are you currently supervising?

$0-1$

2- 3

$4-5$

$6-7$

8-9

$10+$

Are you in a clinical setting in which there are other ACls supervising other ATSs?

Yes

No

In your current clinical setting, are you directly supervised on a daily basis by a full-time staff ATC.

Yes

No

Were you supervised by a graduate student $\mathrm{ACl}$ during your own undergraduate experience?

Yes

No 


\section{Learning Styles}

During my ACI training workshop a variety of ATS learning styles were presented?

Strongly Agree

Agree

Neutral

Disagree

Strongly Disagree

The information that I received on learning styles during the $\mathrm{ACl}$ training workshop prepared me to identify the different ATS learning styles utilized.

Strongly Agree

Agree

Neutral

Disagree

Strongly Disagree

I am confident that my clinical instruction is tailored to fit the learning style of the ATS.

Strongly Agree

Agree

Neutral

Disagree

Strongly Disagree

I am able to differentiate between learning styles and teaching styles?

Strongly Agree

Agree

Neutral

Disagree

Strongly Disagree

\section{ACI Responsibilities}

I feel that I possess the clinical skills needed to serve as an effective $\mathrm{ACl}$

Strongly Agree

Agree

Neutral

Disagree

Strongly Disagree

I feel that I possess the clinical knowledge needed to serve as an effective $\mathrm{ACl}$.

Strongly Agree

Agree

Neutral

Disagree

Strongly Disagree

I feel that I am adequately able to serve as a professional mentor.

Strongly Agree

Agree

Neutral

Disagree

Strongly Disagree 
I feel confident in demonstrating legal and ethical behaviors.

Strongly Agree

Agree

Neutral

Disagree

Strongly Disagree

I feel that if a situation arose involving an ATS and improper legal or ethical behavior in my clinical setting, I would be prepared to properly handle the situation.

Strongly Agree

Agree

Neutral

Disagree

Strongly Disagree

I feel confident in my communication skills. (verbal, non-verbal, written, listening, etc)

Strongly Agree

Agree

Neutral

Disagree

Strongly Disagree

I feel confident in my overall supervisory skills.

Strongly Agree

Agree

Neutral

Disagree

Strongly Disagree

I feel confident in my overall instructional skills.

Strongly Agree

Agree

Neutral

Disagree

Strongly Disagree

I feel confident in my overall evaluation skills.

Strongly Agree

Agree

Neutral

Disagree

Strongly Disagree

I feel that if a situation arose involving an ATS and an improper / compromising interpersonal relationship in my clinical setting, I would be prepared to properly handle the situation.

Strongly Agree

Agree

Neutral

Disagree

Strongly Disagree 
I feel that I have a good understanding of my institution's athletic training policies and procedures to serve as an $\mathrm{ACl}$.

Strongly Agree

Agree

Neutral

Disagree

Strongly Disagree

I feel confident in performing a constructive self-evaluation of my skills and performance as an $\mathrm{ACl}$.

Strongly Agree

Agree

Neutral

Disagree

Strongly Disagree

I feel confident in the use of my institution's evaluation tools.

Strongly Agree

Agree

Neutral

Disagree

Strongly Disagree

\section{Evaluation and Feedback of Student Performance}

I felt prepared to evaluate my ATS's first clinical proficiency.

Strongly Agree

Agree

Neutral

Disagree

Strongly Disagree

I feel confident in evaluating a ATS's clinical knowledge.

Strongly Agree

Agree

Neutral

Disagree

Strongly Disagree

I feel confident in evaluating an ATS's clinical skills.

Strongly Agree

Agree

Neutral

Disagree

Strongly Disagree

I feel confident in evaluating an ATS's professional behavior.

Strongly Agree

Agree

Neutral

Disagree

Strongly Disagree 
I feel confident in evaluating an ATS's clinical decision making.

Strongly Agree

Agree

Neutral

Disagree

Strongly Disagree

I feel prepared to give effective positive feedback to the ATS.

Strongly Agree

Agree

Neutral

Disagree

Strongly Disagree

I feel prepared to give effective constructive feedback to the ATS to improve their performance.

Strongly Agree

Agree

Neutral

Disagree

Strongly Disagree

I feel confident in providing students feedback on clinical knowledge.

Strongly Agree

Agree

Neutral

Disagree

Strongly Disagree

I feel confident in providing students feedback on clinical skills.

Strongly Agree

Agree

Neutral

Disagree

Strongly Disagree

I feel confident in providing students feedback on professional behaviors.

Strongly Agree

Agree

Neutral

Disagree

Strongly Disagree

I feel confident in providing students feedback on clinical decision making.

Strongly Agree

Agree

Neutral

Disagree

Strongly Disagree

Which of the following do you feel the most confident in providing feedback?

Clinical knowledge

Clinical skills

Professional behavior

Clinical decision making 


\section{ACI Preparation}

I am aware of the characteristics of an effective clinical instructor.

Strongly Agree

Agree

Neutral

Disagree

Strongly Disagree

I am able utilize the various characteristics of an effective clinical instructor to make me a better ACl.

Strongly Agree

Agree

Neutral

Disagree

Strongly Disagree

I understand the "Teaching / Learning Over Time" concept.

Strongly Agree

Agree

Neutral

Disagree

Strongly Disagree

Overall, I feel that my institution's ACl training workshop prepared me to be an effective $\mathrm{ACl}$ in my first year.

Strongly Agree

Agree

Neutral

Disagree

Strongly Disagree

Overall, I feel that my institution's ACl training workshop was beneficial to me as an $\mathrm{ACl}$.

Strongly Agree

Agree

Neutral

Disagree

Strongly Disagree

In my opinion, an ATC with one year of clinical experience and completion of an ACl training workshop should serve as an $\mathrm{ACl}$.

Strongly Agree

Agree

Neutral

Disagree

Strongly Disagree 


\section{ACI Greatest Challenges}

In retrospect, what do you feel was the greatest challenges of being a first year $\mathrm{ACl}$ ? (Please rank your top 3, $1=$ the item in which you are most comfortable. Not all answers will have a response.)

Experienced no challenges as an graduate assistant $\mathrm{ACl}$

Understanding institutional policies / procedures

Controlling the learning environment

Time Constraints

-----

Communication

Providing feedback on clinical knowledge

Providing feedback on clinical skills

Providing feedback on professional behaviors

Evaluation of clinical knowledge

------

Evaluation of clinical skills

Evaluation of professional behaviors

Evaluation of clinical proficiencies

Overall, how would you rate your performance in your first year serving as an $\mathrm{ACl}$. (zero being the worst performance and ten being the best performance)

Please use this space to provide any additional comments.

Thank you for taking the time to fill out the questionnaire on graduate assistant ACI preparedness.

If you have any questions or would like to contact me regarding my results feel free to email me at ahart7@mix.wvu.edu . 


\section{APPENDIX D}

\section{ADDITIONAL RESULTS}

Table D1. Demographic Information:

Are you a graduate student?

Percentage Frequency

Yes $\quad 52.60 \% \quad 20$

No $\quad 47.40 \% \quad 18$

Are you an approved clinical instructor (ACI)?

$\begin{array}{rrr}\text { Yes } & 100 \% & 38 \\ \text { No } & 0 \% & \end{array}$

Are you in a clinical setting in which there are other ACIs supervising other ATSs?

$\begin{array}{rrr}\text { Yes } & 78.90 \% & 30 \\ \text { No } & 21.10 \% & 8\end{array}$

In your current clinical setting, are you directly supervised on a daily basis by a fulltime staff ATC

$\begin{array}{lll}\text { Yes } & 31.60 \% & 12 \\ \text { No } & 68.40 \% & 26\end{array}$

Were you supervised by a graduate student ACI during your own undergraduate experience?

Yes $\quad 42.10 \% \quad 16$

How many years have you been an ACI?

$\begin{array}{rrr}\text { Less than one year } & 34.20 \% & 13 \\ \text { One Year } & 7.90 \% & 3 \\ \text { One to two years } & 13.20 \% & 5 \\ \text { Two years } & 21.10 \% & 8 \\ \text { More than two years } & 23.70 \% & 9\end{array}$

How many years have you been a certified athletic trainer (ATC)?

Less than one year

One Year One to two years

Two years

More than two years

$\begin{array}{rr}2.60 \% & 1 \\ 23.70 \% & 9 \\ 10.50 \% & 4 \\ 63.20 \% & 24\end{array}$

What is your current clinical setting?

$\begin{array}{rrr}\text { College/University } & 84.20 \% & 32 \\ \text { High School } & 5.30 \% & 2 \\ \text { Clinic } & 5.30 \% & 2 \\ \text { Other } & 5.30 \% & 2\end{array}$

How many athletic training students (ATS) are you currently supervising

\begin{tabular}{rrr}
0 to 1 & $23.70 \%$ & 9 \\
2 to 3 & $50.00 \%$ & 19 \\
4 to 5 & $18.40 \%$ & 7 \\
6 to 7 & $5.30 \%$ & 2 \\
$10+$ & $2.60 \%$ & 1 \\
\hline
\end{tabular}


Table D2. Learning Styles:

Percentage Frequency

During my ACI training workshop a variety of ATS learning styles were presented?

$\begin{array}{rrr}\text { Strongly Agree } & 39.50 \% & 15 \\ \text { Agree } & 50.00 \% & 19 \\ \text { Neutral } & 5.30 \% & 2 \\ \text { Disagree } & 5.30 \% & 2 \\ \text { Strongly Disagree } & 0.00 \% & 0\end{array}$

The information that I received on learning styles during the ACI training workshop prepared me to identify the different ATS learning styles utilized

$\begin{array}{rrr}\text { Strongly Agree } & 18.40 \% & 7 \\ \text { Agree } & 60.50 \% & 23 \\ \text { Neutral } & 10.50 \% & 4 \\ \text { Disagree } & 10.50 \% & 4 \\ \text { Strongly Disagree } & 0.00 \% & 0\end{array}$

I am confident that my clinical instruction is tailored to fit the learning style of the ATS

$\begin{array}{rrr}\text { Strongly Agree } & 15.80 \% & 6 \\ \text { Agree } & 65.80 \% & 25 \\ \text { Neutral } & 15.80 \% & 6 \\ \text { Disagree } & 2.60 \% & 1 \\ \text { Strongly Disagree } & 0.00 \% & 0\end{array}$

I am able to differentiate between learning styles and teaching styles?

\begin{tabular}{rrr} 
Strongly Agree & $15.80 \%$ & 6 \\
Agree & $57.90 \%$ & 22 \\
Neutral & $18.40 \%$ & 7 \\
Disagree & $7.90 \%$ & 3 \\
Strongly Disagree & $0.00 \%$ & 0 \\
\hline
\end{tabular}


Table D3. ACI Responsibilities:

I feel that I possess the clinical skills needed to serve as an effective ACI

Percentage Frequency

Strongly Agree $\quad 28.90 \% \quad 11$

Agree $\quad 63.20 \% \quad 24$

Neutral $\quad 5.30 \% \quad 2$

Disagree $\quad 2.60 \% \quad 1$

Strongly Disagree $\quad 0.00 \% \quad 0$

I feel that I possess the clinical knowledge needed to serve as an effective ACI.

$\begin{array}{rrr}\text { Strongly Agree } & 39.50 \% & 15 \\ \text { Agree } & 55.30 \% & 21 \\ \text { Neutral } & 2.60 \% & 1 \\ \text { Disagree } & 2.60 \% & 1 \\ \text { Strongly Disagree } & 0.00 \% & 0 \\ \text { Strongly Agree } & 36.80 \% & 14 \\ \text { Agree } & 60.50 \% & 23 \\ \text { Neutral } & 0.00 \% & 0 \\ \text { Disagree } & 2.60 \% & 1 \\ \text { Strongly Disagree } & 0.00 \% & 0 \\ & & \\ \text { Strongly Agree } & 57.90 \% & 22 \\ \text { Agree } & 42.10 \% & 16 \\ \text { Neutral } & 0.00 \% & 0 \\ \text { Disagree } & 0.00 \% & 0 \\ \text { Strongly Disagree } & 0.00 \% & 0\end{array}$

I feel that if a situation arose involving an ATS and improper legal or ethical behavior in my clinical setting, I would be prepared to properly handle the situation.

$\begin{array}{rrr}\text { Strongly Agree } & 39.50 \% & 15 \\ \text { Agree } & 55.30 \% & 21 \\ \text { Neutral } & 0.00 \% & 0 \\ \text { Disagree } & 5.30 \% & 2 \\ \text { Strongly Disagree } & 0.00 \% & 0\end{array}$

I feel confident in my communication skills. (verbal, non-verbal, written, listening, etc)

$\begin{array}{rrr}\text { Strongly Agree } & 34.20 \% & 13 \\ \text { Agree } & 57.90 \% & 22 \\ \text { Neutral } & 5.30 \% & 2 \\ \text { Disagree } & 2.60 \% & 1 \\ \text { Strongly Disagree } & 0.00 \% & 0 \\ & & \\ \text { Strongly Agree } & 23.70 \% & 9 \\ \text { Agree } & 63.20 \% & 24 \\ \text { Neutral } & 10.50 \% & 4 \\ \text { Disagree } & 2.60 \% & 1 \\ \text { Strongly Disagree } & 0.00 \% & 0\end{array}$


I feel confident in my overall instructional skills

$\begin{array}{rrr}\text { Strongly Agree } & 21.10 \% & 8 \\ \text { Agree } & 68.40 \% & 26 \\ \text { Neutral } & 7.90 \% & 3 \\ \text { Disagree } & 2.60 \% & 1 \\ \text { Strongly Disagree } & 0.00 \% & 0\end{array}$

I feel confident in my overall evaluation skills

$\begin{array}{rrr}\text { Strongly Agree } & 26.30 \% & 10 \\ \text { Agree } & 71.10 \% & 27 \\ \text { Neutral } & 0.00 \% & 0 \\ \text { Disagree } & 2.60 \% & 1 \\ \text { Strongly Disagree } & 0.00 \% & 0\end{array}$

I feel that if a situation arose involving an ATS and an improper / compromising interpersonal relationship in my clinical setting, I would be prepared to properly handle the situation

$\begin{array}{rrr}\text { Strongly Agree } & 34.20 \% & 13 \\ \text { Agree } & 57.90 \% & 22 \\ \text { Neutral } & 5.30 \% & 2 \\ \text { Disagree } & 2.60 \% & 1 \\ \text { Strongly Disagree } & 0.00 \% & 0\end{array}$

I feel that I have a good understanding of my institution's athletic training policies and procedures to serve as an ACI

$\begin{array}{rrr}\text { Strongly Agree } & 36.80 \% & 14 \\ \text { Agree } & 50.00 \% & 19 \\ \text { Neutral } & 5.30 \% & 2 \\ \text { Disagree } & 5.30 \% & 2 \\ \text { Strongly Disagree } & 2.60 \% & 1\end{array}$

I feel confident in performing a constructive self-evaluation of my skills and performance as an $\mathrm{ACI}$

$\begin{array}{rrr}\text { Strongly Agree } & 34.20 \% & 13 \\ \text { Agree } & 60.50 \% & 23 \\ \text { Neutral } & 5.30 \% & 2 \\ \text { Disagree } & 0.00 \% & 0 \\ \text { Strongly Disagree } & 0.00 \% & 0\end{array}$

I feel confident in the use of my institution's evaluation tools

$\begin{array}{rrr}\text { Strongly Agree } & 31.60 \% & 12 \\ \text { Agree } & 65.80 \% & 25 \\ \text { Neutral } & 2.60 \% & 1 \\ \text { Disagree } & 0.00 \% & 0 \\ \text { Strongly Disagree } & 0.00 \% & 0\end{array}$


Table D4. Evaluation and Feedback of Student Performance:

I felt prepared to evaluate my ATS's first clinical proficiency

Percentage Frequency

Strongly Agree
Agree
Neutral
Disagree
Strongly Disagree

$\begin{array}{rr}28.90 \% & 11 \\ 63.20 \% & 24 \\ 2.60 \% & 1 \\ 5.30 \% & 2 \\ 0.00 \% & 0\end{array}$

I feel confident in evaluating a ATS's clinical knowledge

$\begin{array}{rrr}\text { Strongly Agree } & 36.80 \% & 14 \\ \text { Agree } & 60.50 \% & 23 \\ \text { Neutral } & 2.60 \% & 1 \\ \text { Disagree } & 0.00 \% & 0 \\ \text { Strongly Disagree } & 0.00 \% & 0\end{array}$

I feel confident in evaluating an ATS's clinical skills

$\begin{array}{rrr}\text { Strongly Agree } & 42.10 \% & 16 \\ \text { Agree } & 55.30 \% & 21 \\ \text { Neutral } & 2.60 \% & 1 \\ \text { Disagree } & 0.00 \% & 0 \\ \text { Strongly Disagree } & 0.00 \% & 0\end{array}$

I feel confident in evaluating an ATS's professional behavior

$\begin{array}{rrr}\text { Strongly Agree } & 47.40 \% & 18 \\ \text { Agree } & 47.40 \% & 18 \\ \text { Neutral } & 5.30 \% & 2 \\ \text { Disagree } & 0.00 \% & 0 \\ \text { Strongly Disagree } & 0.00 \% & 0\end{array}$

I feel confident in evaluating an ATS's clinical decision making

$\begin{array}{rrr}\text { Strongly Agree } & 42.10 \% & 16 \\ \text { Agree } & 57.90 \% & 22 \\ \text { Neutral } & 0.00 \% & 0 \\ \text { Disagree } & 0.00 \% & 0 \\ \text { Strongly Disagree } & 0.00 \% & 0\end{array}$

$\begin{array}{rrr}\text { Strongly Agree } & 47.40 \% & 18 \\ \text { Agree } & 50.00 \% & 19 \\ \text { Neutral } & 2.60 \% & 1 \\ \text { Disagree } & 0.00 \% & 0 \\ \text { Strongly Disagree } & 0.00 \% & 0\end{array}$

I feel prepared to give effective constructive feedback to the ATS to improve their performance

$\begin{array}{rrr}\text { Strongly Agree } & 42.10 \% & 16 \\ \text { Agree } & 50.00 \% & 19 \\ \text { Neutral } & 5.30 \% & 2 \\ \text { Disagree } & 2.60 \% & 1 \\ \text { Strongly Disagree } & 0.00 \% & 0\end{array}$


I feel confident in providing students feedback on clinical knowledge

$\begin{array}{rrr}\text { Strongly Agree } & 39.50 \% & 1 \\ \text { Agree } & 55.30 \% & 2 \\ \text { Neutral } & 2.60 \% & \\ \text { Disagree } & 2.60 \% & \\ \text { Strongly Disagree } & 0.00 \% & \end{array}$

I feel confident in providing students feedback on clinical skills

$\begin{array}{rrr}\text { Strongly Agree } & 39.50 \% & 15 \\ \text { Agree } & 57.90 \% & 22 \\ \text { Neutral } & 2.60 \% & 1 \\ \text { Disagree } & 0.00 \% & 0 \\ \text { Strongly Disagree } & 0.00 \% & 0\end{array}$

I feel confident in providing students feedback on professional behaviors

$\begin{array}{rrr}\text { Strongly Agree } & 44.70 \% & 17 \\ \text { Agree } & 52.60 \% & 20 \\ \text { Neutral } & 2.60 \% & 1 \\ \text { Disagree } & 0.00 \% & 0 \\ \text { Strongly Disagree } & 0.00 \% & 0\end{array}$

I feel confident in providing students feedback on clinical decision making

$\begin{array}{rrr}\text { Strongly Agree } & 42.10 \% & 16 \\ \text { Agree } & 55.30 \% & 21 \\ \text { Neutral } & 2.60 \% & 1 \\ \text { Disagree } & 0.00 \% & 0 \\ \text { Strongly Disagree } & 0.00 \% & 0\end{array}$

Which of the following do you feel the most confident in providing feedback?

$\begin{array}{rrr}\text { Clinical Knowledge } & 18.40 \% & 7 \\ \text { Clinical Skills } & 31.60 \% & 12 \\ \text { Professional Behavior } & 34.20 \% & 13 \\ \text { ical Decision Making } & 15.80 \% & 6\end{array}$


Table D5. ACI Preparation:

Percentage Frequency

I am aware of the characteristics of an effective clinical instructor

$\begin{array}{rrr}\text { Strongly Agree } & 28.90 \% & 11 \\ \text { Agree } & 63.20 \% & 24 \\ \text { Neutral } & 2.60 \% & 1 \\ \text { Disagree } & 5.30 \% & 2 \\ \text { Strongly Disagree } & 0.00 \% & 0\end{array}$

I am able utilize the various characteristics of an effective clinical instructor to make me a better ACI.

$\begin{array}{rrr}\text { Strongly Agree } & 21.10 \% & 8 \\ \text { Agree } & 68.40 \% & 26 \\ \text { Neutral } & 5.30 \% & 2 \\ \text { Disagree } & 5.30 \% & 2 \\ \text { Strongly Disagree } & 0.00 \% & 0 \\ & & \\ \text { Strongly Agree } & 36.80 \% & 14 \\ \text { Agree } & 50.00 \% & 19 \\ \text { Neutral } & 7.90 \% & 3 \\ \text { Disagree } & 5.30 \% & 2 \\ \text { Strongly Disagree } & 0.00 \% & 0\end{array}$

Overall, I feel that my institution's ACI training workshop prepared me to be an effective ACI in my first year

$\begin{array}{rrr}\text { Strongly Agree } & 18.40 \% & 7 \\ \text { Agree } & 39.50 \% & 15 \\ \text { Neutral } & 26.30 \% & 10 \\ \text { Disagree } & 15.80 \% & 6 \\ \text { Strongly Disagree } & 0.00 \% & 0\end{array}$

Overall, I feel that my institution's ACI training workshop was beneficial to me as an ACI

$\begin{array}{rrr}\text { Strongly Agree } & 18.40 \% & 7 \\ \text { Agree } & 42.10 \% & 16 \\ \text { Neutral } & 26.30 \% & 10 \\ \text { Disagree } & 13.20 \% & 5 \\ \text { Strongly Disagree } & 0.00 \% & 0\end{array}$

In my opinion, an ATC with one year of clinical experience and completion of an ACI training workshop should serve as an ACI

$\begin{array}{rrr}\text { Strongly Agree } & 13.20 \% & 5 \\ \text { Agree } & 36.80 \% & 14 \\ \text { Neutral } & 23.70 \% & 9 \\ \text { Disagree } & 23.70 \% & 9 \\ \text { Strongly Disagree } & 2.60 \% & 1\end{array}$




\section{Table D6. Approved Clinical Instructors Greatest Challenges:}

In retrospect, what do you feel was the greatest challenges of being a first year ACI?

Understanding institutional policies/procedures

Greatest $\%$ Frequency Intermediate $\%$

Controlling the learning environment

$18.40 \%$

7

$2.60 \%$

Time constraints

$2.60 \% \quad 1 \quad 21.10 \%$

Communications

$15.80 \%$

6

$13.20 \%$

Providing feedback on clinical knowledge

$\begin{array}{lll}7.90 \% & 3 & 5.30 \%\end{array}$

Providing feedback on clinical skills

$10.50 \% \quad 4 \quad 7.90 \%$

Providing feedback on professional behaviors

$5.30 \% \quad 2.60 \%$

Evaluation of clinical knowledge

$10.50 \% \quad 4.90 \%$

Evaluation of clinical skills

$2.60 \% \quad 1 \quad 7.90 \%$

Evaluation of professional behaviors

$5.30 \%$

2

$2.60 \%$

Evaluation of clinical proficiencies

$0.00 \% \quad 0 \quad 5.30 \%$

Overall, how would you rate your performance in your first year serving as an ACI (0-10) 


\section{APPENDIX E \\ RECOMMENDATIONS FOR FUTURE RESEARCH}

1. A recommendation for future research is to bring the questionnaire to a convention or conference where you will be able to improve upon the amount of responses and increase the sample size.

2. Another recommendation is to create a questionnaire for the CI to respond to asking about the discrepancies found in the preexisting literature and this study.

3. A suggestion would be to use a questionnaire for all levels of experience and then compare the novice ACI responses to the experienced responses and try to understand where the discrepancy lies.

4. A more defined definition of what professional behaviors are classified as may help participants to respond to the questionnaire more effectively.

5. A questionnaire for program directors which asks about their perceptions of novice ACIs and how they perform as clinical educators may also help to understand where the discrepancy lies. 


\section{ADDITIONAL REFERENCES}

13. Weidner TG, Henning JM. Importance and applicability of approved clinical instructor standards and criteria to certified athletic trainers in different clinical education settings. $J$ Athl Train. 2005;40:326-332.

14. Laurent T, Weidner TG. Clinical instructors' and student athletic trainers' perceptions of helpful clinical instructor characteristics. J Athl Train. 2001;36:58-61.

15. Pitney WA, Ehlers G, Walker S. A descriptive study of athletic training students' perceptions of effective mentoring roles. The Inter J of Allied Health Sci and Prac. 2006;4:1-8.

16. Pircher CM. Perceived Preparedness of Graduate Assistant Novice Approved Clinical Instructors for Supervision of Undergraduate Athletic Training Students. [master's thesis]. Morgantown, WV: West Virginia University; 2008.

17. Curtis N, Helion JG, Domsohn M. Student athletic trainer perceptions of clinical supervisor behaviors: A Critical Incident Study J Athl Train. 1998;33:249-253.

18. NATA Education Council. Available at:www.nataec.org. Accessed July 10, 2008.

19. Weidner TG, Henning JM. Historical perspective of athletic training clinical education. $J$ Athl Train. 2002;37:222-228.

20. Board of Certification for the Athletic Trainer. Available at: http://www.bocatc.org/index.php?option=com_content\&task=view\&id=100\&Itemid=105. Accessed July 8, 2008.

21. Lauber CA, Tith PE, Leary PA, Martin D, Killian CB. Program directors' and clinical instructors' perception of important clinical-instructor behavior categories in the delivery of athletic training clinical instruction. J Athl Train. 2003;38(4):336-341.

22. Amato HK, Konin JG, Brader H. A model for learning over time: the big picture. J Athl Train. 2002;37:236-240.

23. Pitney WA, Ehlers GG. A grounded theory study of the mentoring process involved with undergraduate athletic training students. J Athl Train. 2004;39:344- 351.

24. Panseri ML. An Exploration of Mentoring in Athletic Training Clinical Education: Established a Preliminary Model Based on the Grounded Theory [master's thesis]. Morgantown, WV: West Virginia University; 2005. 
25. Anderson MB, Larson GA, Luebe JJ. Student and supervisor perceptions of the quality of supervision in athletic training education. J Athl Train. 1997;32:328-332.

26. Delforge GD, Behnke RS. The history and evolution of athletic training education in the united states J Athl Train. 1999;34:53-61.

27. Harrelson GL, Leaver-Dunn D, Wright KE. An assessment of learning styles among undergraduate athletic training students. J Athl Train. 1998;33:50- 53.

28. Commission on Accreditation of Athletic Training Education. Available at: www.CAATE.net. Accessed July 10, 2008.

29. Giordano S. Improving clinical instruction: comparison of literature. Rad Tech. 2008;79:289296.

30. Brower KA, Stemmans CL, Ingersoll CD, Langley DJ. An investigation of undergraduate athletic training students' learning styles and program admission success. $J$ Athl Train. 2001;36:130-135.

31. Unsworth CA. The clinical reasoning of novice and expert occupational therapists. Scandinavian J of Occupational Ther. 2001;8:163-173.

32. Weidner TG, Henning JM. Development of standards and criteria for the selection, training, and evaluation of athletic training approved clinical instructors. $J$ Athl Train. 2004;39:335343.

33. Weidner TG, Pipkin J. Clinical supervision of athletic training students at colleges and universities need improvement. J Athl Train. 2002;37:241-247.

34. Approved Clinical Instructor West Virginia University Athletic Training Curriculum Clinical Education. 2007-2008.

35. Barnum MG. Questioning skills demonstrated by ACI during clinical field experiences. $J$ Athl Train. 2008;43(3):284-292.

36. Armstong N. Role modeling in the clinical workplace. British Journal of Midwifery. 2008;16:596-603.

37. Jarski RW, Kulig K, Olson RE. Clinical teaching in physical therapy: student and teacher perceptions. Phys Ther. 1990;70(3):173-178.

38. Giles S, Wetherbee E, Johnson S. Qualifications and credentials of clinical instructors supervising physical therapist students. J of Phys Ther Edu. 2003.

39. Henning JM, Weidner TG. Role Strain in collegiate athletic training approved clinical 
instructors. J Athl Train. 2008;43:275-283.

40. Weidner TG, Henning JM. Being an effective athletic training clinical instructor. Athl Ther Today. 2002;7(5):6-11.

41. Platt Meyer L. Athletic training clinical instructor as situational leaders. $J$ Athl Train. 2002;37:261-265.

42. Laurent TG, Bradney DA. Leadership behaviors of athletic training leaders compared with leaders in other fields. J Athl Train. 2007;42:120-125.

43. Craig DI. Learning professionalism in athletic training education. Athl Train Edu J. 2006;1(Jan-Mar):8-11.

44. Lauber CA. The Effect of Role, Age, Gender and Years if Experience Upon The Perceived Importance of Clinical Teaching Behavior Categories in Athletic Training Education. [master's thesis]. Morgantown, WV: West Virginia University, 2001.

45. Berry DC, Miller MG, Berry LM. Effects of clinical field-experience setting on athletic training students' perceived percentage of time spent on active learning. J Athl Train. 2004;39(2):176-184.

46. Stemmans CL, Gangstead SK. Athletic training students initiate behaviors less frequently when supervised by novice clinical instructors. J Athl Train. 2002;37:255-260.

47. Seegmiller JG: A model for clinical education in athletic training. The Inter $J$ of Allied Health Sci and Prac. 2003. Volume 1 Number 1.

48. Seegmiller JG. Perceptions of quality for graduate athletic training education. $J$ Athl Train. 2006;41(4):415-421.

49. Wilcoxson MA. The Socialization of Athletic Training Clinical Instructors: A Descriptive Study [Doctoral Dissertation]. West Lafayette, IN: Purdue University; 2007.

50. Brower KA, Stemmans CL, Ingersoll CD, Langley DJ. An investigation of undergraduate athletic training students' learning styles and program admission success. J Athl Train. 2001;36:130-135. 